\title{
Stimulation Therapies and the Relevance of Fractal Dynamics to the Treatment of Diseases
}

\author{
Weyland Cheng1,2*, Peter K. Law ${ }^{1,2}$, Hon C. Kwan ${ }^{3}$, Richard S. S. Cheng ${ }^{4}$ \\ ${ }^{1}$ Department of Biomedical Engineering, Huazhong University of Science and Technology, Wuhan, China \\ ${ }^{2}$ Cell Therapy Institute, Wuhan, China \\ ${ }^{3}$ Department of Physiology, Faculty of Medicine, University of Toronto, Toronto, Canada \\ ${ }^{4}$ St. Joseph's Health Centre, University of Toronto, Toronto, Canada \\ Email: ${ }^{*}$ wey c@hotmail.com
}

Received 9 September 2014; revised 9 October 2014; accepted 21 October 2014

Copyright (C) 2014 by authors and Scientific Research Publishing Inc.

This work is licensed under the Creative Commons Attribution International License (CC BY). http://creativecommons.org/licenses/by/4.0/

(c) (i) Open Access

\section{Abstract}

This paper provides an overview of the conventional therapeutic stimulation methodologies and proposes a more effective stimulation approach based on a consideration of the inherently fractal nature of normal biological dynamics. There are varying forms of physiological stimulations including the use of electrical currents, electromagnetic fields, temperature change, ultrasound, light and so forth. These stimulation therapies can be categorized into three main modalities: electrical stimulation modalities, thermal modalities, and non-thermal modalities. Electrical stimulation modalities include therapeutic techniques where electrical current is directly applied to the body of treated subject. Direct application of electrical current to the brain also falls under this category. Thermal modalities consist of stimulations that induce temperature change on the body for therapeutic effects without the direct transfer of electrical current. Non-thermal modalities functions through energy transfer without directly applying electrical current and without the effects of temperature change. A fourth miscellaneous category for stimulation techniques consists of the stimulation effects of music along with physical stimulation as in massage therapy. Common to most of these therapeutic strategies is that the stimulation is delivered at certain fixed periods or frequencies. We introduce some rudiments of fractal dynamics, and the notions of self-similarity, scale-invariance, and long-range correlation or memory in the dynamics of a system. We present evidence that fractal dynamics is commonly observed in healthy physiological systems while unhealthy systems are shown to veer away from fractal dynamics towards periodic or random motion. This difference in dynamics can be observed in many biological signals such as in neural activity, heart rate variations, and breathing patterns. We propose that an optimal stimulation technique should thus be one that encourages an unhealthy, non-fractal pathological system

\footnotetext{
${ }^{*}$ Corresponding author.
} 
towards a healthy, fractal dynamic. Given the ubiquity of fractality in healthy biological dynamics, we argue that a fractal pattern of stimulation is a more optimal approach to functional restoration than the widely used conventional periodic stimulation, which may further consolidate the existing pathological dynamics.

\section{Keywords}

\section{Fractal, Stimulation Pattern, Electrophysical Agents, Stimulation Devices, Electrotherapy}

\section{Introduction}

Numerous therapeutic devices currently exist with the purpose of treating diseases through an externally generated form of stimulation. The forms of these stimuli include direct electric current, magnetic and electromagnetic stimulation, ultrasound, light, temperature change through convection, conduction or conversion, physical pressure, and auditory transfer. When employed under the appropriate conditions, these stimuli are shown to have a beneficial physiological effect on the treated subject. Electrophysical agents (EPA's) operate on the basis of transferring energy to a physiological system and may be categorized into electrical stimulation, thermal and non-thermal modalities [1]. Direct electrical stimulation can excite sensory and motor nerves when applied to parts of the body as well as alter physiological healing processes through an electric field. Both electrical and non-thermal modalities can also play a role in mental health by assisting the alteration of the chemical makeup of the brain and influencing the synaptic plasticity of the brain. Thermal stimulation modalities function by using temperature to influence blood flow, inflammation, edema, metabolic activity and the extensibility of collagen tissue [2]. While some treatments are more developed or understood than others, the most effective method for the design and application of these devices is not apparent. Majority of existing stimulation devices emit periodic patterns for treatment, yet the efficacy of this method may not be optimal.

A look into the nature and concept of fractal dynamics in physiological networks may indicate a novel theory on how stimulation therapy can be better approached. In the field of nonlinear dynamics and chaos, fractals are a well-known phenomenon that exhibit scale-invariance and self-similarity in its dynamics. Fractals can be observed and applied in multiple disciplines including but not limited to nature, astronomy, computer science, fluid mechanics, physics and medicine. Nature, for instance, reveals its inherent fractality through geometrical structures, such as the bifurcation or pattern of tree branches, lightening, snowflakes, and the tributary network of rivers. This spatial self-similarity is in stark contrast to the repetitive or unpredictable nature of periodic or chaotic dynamic systems, respectively. The concept of fractal can also be applied to temporal fluctuations. For instance in economics, the recession and growth of the economy as well as the rise and fall of the stock market portrays a time-dependent, self-similar pattern [3].

Fractality is widely observed in physiological processes. Fractal characteristics are observed in the physiological variables recorded from normal, healthy individuals while unhealthy individuals show periodic or chaotic dynamics. These findings have been evident in physiological measurements as in the electroencephalogram (EEG), breathing pattern, heart rate, oxygen saturation level and blood cell dynamics of healthy individuals and patients [4]-[7]. These general observations suggest that the restoration of normal fractal dynamics and hence function is the central role of the stimulation methodology, and raise the question as to whether the periodic pattern of stimulation in widespread use is optimal in promoting a return to aperiodic, healthy fractal dynamics.

This paper will examine physiological stimulation modalities and their effectiveness along with the concept of fractal dynamics, its relevance to human pathophysiology, and its potential application towards stimulation therapy.

\section{Therapeutic Stimulation Devices}

Numerous stimulation therapies have been scientifically confirmed while others are considered to be closer to a pseudoscience. The field of therapeutic stimulations covers a wide range of techniques where the stimulation method can exist in varying forms such as the direct transmission of electrical current, thermal energy, nonthermal energy, physical force or auditory output. Electrical current, thermal and non-thermal energy stimulations may be categorized under electrotherapies. 


\subsection{Overview}

There is some debate about the terminology of electrotherapy modalities and their classifications. This paper will interpret electrotherapy as electrophysical agents (EPA's) and classify the types of EPA's into electrical stimulation agents/modalities, thermal agents/modalities, and non-thermal agents/modalities (see Table 1) [1]. While not every EPA is accounted for and stimulation therapies are not limited to just EPA's, the objective in this section is to examine underlying concepts of stimulation techniques. Thereby, the effectiveness, mechanisms and implementation of selected treatment therapies will be examined with the goal of obtaining a deeper understanding of the interaction between the stimuli and physiological system, while opening to the possibility of optimizing all stimulation therapy modalities.

\subsection{Electrical Stimulation Modalities}

Electrical stimulation modalities deliver small electrical currents through electrodes to the skin or bodily tissue of the treated subject to induce therapeutic effects to the relevant area of the body. They differ in comparison to thermal and non-thermal modalities by directly conducting electricity to alter physiological mechanisms within the body. A large portion of electrical stimulation modalities are used to treat musculoskeletal injuries or conditions by stimulating the peripheral nervous system (PNS) as well as neurological disorders involving the central nervous system (CNS).

A common modality shall be selected for the introduction of electrical stimulation modalities. Transcutaneous electrical nerve stimulation (TENS) is a well-known modality largely used for the management of pain. TENS delivers biphasic electrical pulses through electrodes that are attached to the surface of the skin. High frequency $(>50 \mathrm{~Hz})$ currents with low intensities are generally used to stimulate sensory nerves while low frequency $(<10$ $\mathrm{Hz}$ ) currents with high intensities are used to stimulate motor nerves [8].

Table 1. Classification of electrotherapy modules or electrophysical agents. ${ }^{a}$

\begin{tabular}{|c|c|c|}
\hline Electrical Stimulation Agents/Modalities (A) & Thermal Agents/Modalities (B) & Non-Thermal Agents/Modalities (C) \\
\hline Transcutaneous Electrical Nerve Stimulation (TENS) & Infra Red Radiation (IRR) & [Pulsed] Ultrasound \\
\hline $\begin{array}{c}\text { Interferential Therapy (IFT)/Interferential } \\
\text { Current (IFC) }\end{array}$ & Shortwave Diathermy (SWD) & $\begin{array}{l}\text { Low Intensity Pulsed } \\
\text { Ultrasound (LIPUS) }\end{array}$ \\
\hline Faradic Stimulation & Microwave Diathermy (MWD) & [Pulsed] Shortwave Therapy (PSWT) \\
\hline $\begin{array}{c}\text { Neuromuscular Electrical Stimulation (NMES), } \\
\text { Electrical Muscle Stimulation (EMS) }\end{array}$ & $\begin{array}{c}\text { Other Radio Frequency (RF) } \\
\text { Therapies }\end{array}$ & $\begin{array}{c}\text { [Pulsed] Laser Therapy: Low-Level } \\
\text { Laser Therapy (LLLT)/Low Intensity } \\
\text { Laser Therapy (LILT) }\end{array}$ \\
\hline Functional Electrical Stimulation (FES) & Hydrocollator Packs & Low Intensity RF Applications \\
\hline Iontophoresis & Wax Therapy & Pulsed Electromagnetic Field (PEMF) \\
\hline Galvanic Stimulation & Hydrotherapy & Ultraviolet Radiation (UVR) \\
\hline $\begin{array}{l}\text { Twin Peak Monophasic Stimulation or High } \\
\text { Voltage Pulsed Galvanic Stimulation (HVPGS) }\end{array}$ & Fluidotherapy & Phototherapy \\
\hline Diadynamic Therapy & Ultrasound Therapy & Electrical Brain Stimulation (EBS) \\
\hline H Wave Therapy; Action Potential Stimulation (APS) & Laser Therapy & Pulsed Magnetic Therapy \\
\hline Russian Stimulation: Medium Frequency Stimulation & $\begin{array}{c}\text { Cryotherapy/Cold } \\
\text { Therapy/Ice/Immersion Therapy }\end{array}$ & [Pulsed] Ultrasound \\
\hline $\begin{array}{l}\text { Rehabilitation Box (Rebox) Therapy; Self-controlling } \\
\text { Energy Neuro Adaptive Regulator (SCENAR) Therapy }\end{array}$ & Infra Red Radiation (IRR) & \\
\hline $\begin{array}{l}\text { Microcurrent Therapy (MCT), Microcurrent } \\
\text { Electrical Neuromuscular Stimulation (MENS) or } \\
\text { [Pulsed] Low-Intensity Direct Current (LIDC) }\end{array}$ & Shortwave Diathermy (SWD) & \\
\hline Electrical Brain Stimulation (EBS) & & \\
\hline
\end{tabular}

\footnotetext{
${ }^{\mathrm{a}}$ Adapted from Reference [1].
} 
Both peripheral and central nerves can be affected in TENS. The gate-control theory of pain and endogenous opioid system are the two theoretical underlying mechanisms that support the use of TENS. The gate-control theory of pain, originated by Ronald Melzack and Patrick Wall, reveals the reduction of the transmission of nociceptive $\mathrm{C}$-fibers in the spinal cord by means of exciting the mechanoreceptive $\mathrm{A}$ beta $(\mathrm{A} \beta)$ sensory fibers at high frequency $(90-130 \mathrm{~Hz}$ ) [9]. The excitation of A $\beta$ fibers has also been shown to suppress A delta (A $\delta$ ) fiber nociceptive processing [10]. These results support the theory that a neural gate mechanism with secondary afferent neurons in the dorsal horn of the spinal cord exists. Inhibitory neurons in the spinal cord prevent pain signals from reaching the brain unless the stimulation of small diameter fibers (A $\delta$ and C fiber) occur, thereby opening the neural gate for pain signals to pass through. The activation of the lower threshold and larger diameter $\mathrm{A} \beta$ fiber reduces the noxious stimuli of $\mathrm{A} \delta$ and $\mathrm{C}$ fibers, thus reducing pain.

Using low frequency (2 - $5 \mathrm{~Hz}$ ) to stimulate $\mathrm{A} \delta$ fibers, on the other hand, causes the release of encephalin, an endogenous opiate [11]. Encephalin is a naturally occurring endorphin which regulates nociception and reduces the activation of noxious sensory pathways. Evidence of the release of differing opioids at varying frequencies has also been shown using TENS treatment. Studies have shown the increase of $\beta$ endorphins, enkephalin, dynorphins and opioid agonists [12]-[14] as well as the activation of opioid, serotonin, and muscarinic receptors sites, and the involvement or activation of opioid and $\alpha-2$ noradrenergic receptors [15]-[18].

From the electrophysiological mechanisms of TENS, distinctive techniques to optimize the treatment can be formed. Adjustable parameters that influence the output characteristics of the electrical pulses are the pulse width (duration), pulse rate (frequency), amplitude (intensity), electrode placement and pulse pattern (mode). The effectiveness in varying these parameters has yet to be completely researched and is mostly inconclusive or situation dependent.

As a result, five main TENS modules exist, which are conventional TENS, acupuncture-like TENS (ALTENS), brief intense TENS, burst mode TENS and modulation mode TENS (see Table 2) [19]. These modules differ in the use and pattern of the aforementioned parameters in order to produce the desired pain-relieving effects. Traditional TENS uses constant, periodic short pulses to electrically stimulate at a local site. AL-TENS and brief intense TENS are similar to traditional TENS but with differing frequencies, intensity and pulse widths. Burst mode TENS and modulated TENS consist of slightly more parameter variation than the aforementioned methods and implement more than one type of frequency.

Habituation has been shown to occur under repeated administration of TENS [20] [21]. This accommodation may be due to opioid tolerance as shown in rat studies [22]. Modulation between high and low frequencies show that it is possible to reduce or delay the affects of accommodation [23] [24]. On the other hand, pharmacological

Table 2. Main transcutaneous electrical nerve stimulation (TENS) modules consisting of traditional TENS, acupuncture-like TENS (AL-TENS), brief intense TENS, burst mode TENS and modulation TENS.

\begin{tabular}{|c|c|c|}
\hline \multirow{2}{*}{$\begin{array}{l}\text { TENS } \\
\text { Module }\end{array}$} & \multicolumn{2}{|c|}{ Description } \\
\hline & Parameters & Characteristics \\
\hline $\begin{array}{l}\text { Traditional or } \\
\text { conventional } \\
\text { TENS }\end{array}$ & $\begin{array}{l}\text { Emits short pulses }(50-125 \mu \mathrm{s}) \text { at high frequency } \\
\qquad(90-130 \mathrm{~Hz}) \text { and low intensity. }\end{array}$ & $\begin{array}{l}\text { Stimulates the pain gate mechanism. Results in a } \\
\text { rapid onset of analgesia but the effects do not } \\
\text { remain relatively long post-treatment. }\end{array}$ \\
\hline AL-TENS & $\begin{array}{l}\text { Operates at low frequencies }(2-5 \mathrm{~Hz}) \text { and high intensity } \\
\text { with a pulse width of approximately } 200 \mu \mathrm{s} \text {. }\end{array}$ & $\begin{array}{l}\text { Stimulates the opioid mechanism. Results in a slower } \\
\text { onset of analgesia but the effects last longer compared } \\
\text { to conventional TENS. AL-TENS also causes muscle } \\
\text { contractions due to the stimulation of motor nerves. }\end{array}$ \\
\hline $\begin{array}{c}\text { Brief } \\
\text { intense TENS }\end{array}$ & $\begin{array}{l}\text { Emits a high frequency }(100-150 \mathrm{~Hz}) \text { current with a long } \\
\text { pulse width }(150-250 \mu \mathrm{s}) \text { using an amplitude near the } \\
\text { patient tolerance threshold for a duration of } 15 \text { minutes or less. }\end{array}$ & $\begin{array}{l}\text { Results in a very rapid onset of analgesia with } \\
\text { relatively long lasting effects. Stimulation may } \\
\text { feel uncomfortable due to the high intensity. }\end{array}$ \\
\hline $\begin{array}{l}\text { Burst } \\
\text { mode TENS }\end{array}$ & $\begin{array}{l}\text { Burst mode TENS combines both high and low } \\
\text { frequencies by using a baseline low frequency current } \\
\text { while delivering high frequency bursts of electrical pulses. }\end{array}$ & $\begin{array}{l}\text { Activates both the pain gate and opioid } \\
\text { mechanisms. Burst mode TENS still requires } \\
\text { high intensity, but it is more comfortable } \\
\text { in comparison to brief intense TENS. }\end{array}$ \\
\hline $\begin{array}{l}\text { Modulated } \\
\text { mode TENS }\end{array}$ & $\begin{array}{l}\text { Modulation mode TENS varies the frequency, intensity } \\
\text { or pulse duration through a cyclic sequence starting from } \\
\text { a baseline value to a pre-set value and back again. }\end{array}$ & $\begin{array}{l}\text { The variation in stimulation pattern helps to } \\
\text { reduce accommodation effects. }\end{array}$ \\
\hline
\end{tabular}


solutions have been developed to prevent the tolerance of TENS treatment. Blockade of N-methyl-D-aspartate (NMDA) receptors using MK-801 as a competitive antagonist resulted in the prevention of analgesic tolerance in animal studies [25]. In another study, the blockade of cholecystokinin also prevents the tolerance of opioid [26].

Several TENS-like systems have been developed (see Table 1(A)) which operate under the same concept of delivering electrical current to bodily tissues through electrodes. Most electrical stimulation modalities treat neuromuscular ailments and neuropathies by stimulating neural endings. In contrast, modalities that use microcurrent—as in microcurrent electrical neuromuscular stimulation (MENS), rehabilitation box (rebox) therapy and self-controlling energy neuro adaptive regulator (SCENAR) therapy-operate under a different mechanism other than stimulating the nerve. Less than one milliamp of current is delivered to the body to treat various pain conditions, injuries and wounds. Microcurrent stimulation functions under the theory that the magnitude of the applied current is closer to the magnitude of the actual cellular current of the body. Injuries and defects tend to have a higher electrical resistance which causes the electricity in the body to take a less resistive path around the defect. The application of microcurrent overcomes this barrier and restores the cells to its original healthy frequency while also restoring homeostasis by increasing cellular ATP production, protein synthesis, oxygenation, ion exchange and nutrient absorption [27]-[29]. Furthermore, it decreases inflammation and eliminates cellular waste products. As opposed to blocking the transmission of pain signals like in TENS, microcurrent stimulation promotes the regeneration of damaged tissues.

\subsection{Thermal Modalities}

In contrast to electrical stimulation modalities, thermal modalities operate on the basis of temperature change through non-electrical transfer of energy. Thermal-based therapies may induce heat by conversion techniques such as infrared radiation, electromagnetic energy, radiofrequency, ultrasound or laser. Heat or cold may also be transferred by conduction or convection through the use of physical substances such as hydrocollator packs, wax, water and air (see Table $\mathbf{1}(\mathbf{B})$ ).

Nadler, S.F. (2004) provides a basic review on thermal modality applications and their physiological basis. While most thermal modalities increase the temperature of the treated area, cryotherapy uses substances to remove heat. The possible uses for cryotherapy include relieving acute and chronic pain and muscle spasms as well as decreasing metabolism, blood circulation, inflammation, edema, and extensibility [2]. One study showed a decrease in nerve conduction velocity and an increase in pain threshold and pain tolerance when cryotherapy was applied to the ankle [30]. It was speculated the reduction of conduction velocity occurred in the tibial nerve and based on a previous study, temperature could affect conduction velocity by altering the interaction between $\mathrm{Ca}^{2+}$ and its neural surface receptor, possibly delaying action potential generation [31]. Heat therapy, on the other hand, may be used to reduce pain and muscle spasms while increasing metabolism, blood circulation, inflammation, edema, and extensibility [2]. Similar to TENS, heat therapy is theorized to operate under the principle of inhibiting afferent and efferent $\mathrm{C}$ fibres and/or increasing endorphin levels [32].

An example of a thermal modality is ultrasound therapy (see Table 1(B)). Thermal and non-thermal effects of ultrasound tend to occur simultaneously. However, this paper separates the two treatments based on the intended and more dominant effect. In this manner, there are two main types of ultrasound therapy, one uses high intensity ultrasound causing a thermal effect and the other uses low intensity ultrasound where scattering of energy occurs inducing a non-thermal effect.

Thermal ultrasound therapy uses continuous sound waves causing temperature change in bodily tissue through absorption. In other words, the acoustic energy from the ultrasound converts into kinetic energy in the form of heat. The amount of absorption that occurs depends on the area of treatment as well as the intensity and frequency of the ultrasound. Therapeutic frequencies tend to range from 0.7 to $3.3 \mathrm{MHz}$ while the intensity can range from $1.5 \mathrm{~W} / \mathrm{cm}^{2}$ to $3.0 \mathrm{~W} / \mathrm{cm}^{2}$ [33]. A higher intensity generally correlates to an increase in temperature and the higher the frequency, the greater the absorption rate. The pulsing ratio also has a proportional effect on temperature where a lower duty cycle results in a smaller increase in temperature.

While the focus of this paper is on innoxious stimulation treatments, it should be noted that some thermal modalities use intensities high enough to cause ablations, such as high-intensity focused ultrasound (HIFU). It should also be noted that there is controversy over the usefulness of ultrasound therapy and past reports have stated the ineffectiveness of this treatment for pain and musculoskeletal injuries, the lack of effectiveness for 
pain or soft tissue injury in comparison to a placebo, and the lack of evidence and biophysical rationale of this treatment [34] [35].

\subsection{Non-Thermal Modalities}

Much like thermal modalities, non-thermal modalities may use stimulation techniques involving the emission of energy as in ultrasound, magnetic fields, electromagnetic fields, lasers, ultraviolet light, and radio frequency waves (see Table $1(C)$ ). A key difference in the application of these similar therapeutic techniques is that nonthermal modalities tend to operate under lower intensities and consist of a temporally pulsed output. Unlike thermal modalities, the physiological effects of non-thermal modalities do not depend on temperature change. Rather, the body is affected through non-thermal energy transfer. Contrary to the previous two examples of stimulation modalities, this section will examine the physiological impact of electrotherapy on the brain.

A distinct class of EPA's that falls under electrical stimulation modalities as well as non-thermal modalities are electrical brain stimulation (EBS) techniques for the treatment of mental disorders and ailments. EBS's that fall under electrical stimulation modalities include electroconvulsive therapy, transcranial direct current stimulation (tDCS), deep brain stimulation (DBS) and vagus nerve stimulation (VNS). EBS's of the non-thermal modality include transcranial magnetic stimulation (TMS) and magnetic seizure therapy (MST). Possible modifiable parameters for EBS modalities are the current type (alternating versus direct), polarity of the electrode, frequency, intensity, waveform and pulse pattern [36].

While the mechanisms and etiology of neurological disorders is not fully realized and is still an ongoing science, it was determined that the disturbed connectivity of neural networks is an underlying symptom of these mental diseases [37]-[41]. As a result, extensive research has been performed supporting this notion of dysfunctional connectivity in numerous ailments such as schizophrenia [42]-[46], major depressive disorder (MDD) [47]-[50], attention-deficit hyperactivity disorder (ADHD) [51]-[53], post-traumatic stress disorder (PTSD) [54]-[56], obsessive-compulsive disorder (OCD) [57]-[60], Alzheimer’s disease [61]-[63], Huntington's disease [64]-[66], Parkinson's disease [67]-[70], autism spectrum disorders [71]-[74], and insomnia [75] [76].

The Hebbian theory proposes the concept of synaptic plasticity where the activation of cells strengthens the relevant synaptic network [77]. As an example, if a presynaptic neuron is active and excites a postsynaptic neuron, the synapse strengthens. If a presynaptic neuron is active and the postsynaptic neuron is not active, the strength of the synapse is reduced. Thus, the strength of a synapse is experience-dependent on pre- and postsynaptic activity. It goes to follow that influencing the synaptic connectivity in areas of dysfunction could result in a desired long-term potentiation (LTP) or long-term depression (LTD). LTP signifies the continued effects of synaptic strength post-stimulation while LTD signifies the continued effects of a weakened synapse post-stimulation. Through this concept, EBS modalities were developed to encourage, discourage or reset the electrical connections and induce synaptic plasticity in the brain.

Examining transcranial magnetic stimulation (TMS) as an example modality, TMS is a non-invasive brain stimulation technique using magnetic fields to influence the polarization of neurons in the brain. The therapy is performed through an electromagnetic coil appropriately placed near the head at the area of treatment where electromagnetic pulses are passed through the coil inducing an electrical current in the brain.

A review by Thickbroom, G.W. (2007) summarizes TMS and its possible mechanisms and effects on synaptic plasticity [78]. TMS can stimulate excitatory pathways and generate synaptic activity leading to LTP using a short period of high frequency (generally around $5 \mathrm{~Hz}$ or higher). On the other hand, long periods of low frequency stimulation $(1-5 \mathrm{~Hz})$ can induce depotentiation and lead to LTD.

LTP and LTD are influenced by the same synaptic mechanism involving NMDA and AMPA receptors and the movement of cations [79]-[82]. Consider a model with a pre-synaptic neuron which releases glutamate and a post-synaptic neuron carrying two types of surface glutamate receptors, NMDA and AMPA. The glutamate binds to both post-synaptic receptors, opening a channel allowing certain cations to pass through. AMPA receptors allow mostly $\mathrm{Na}^{+}$and $\mathrm{K}^{+}$ions to pass through resulting in an excitatory post-synaptic current or potential (EPSC or EPSP). While NMDA receptors are permeable to $\mathrm{Ca}^{+2}$, they carry a voltage-gated $\mathrm{Mg}^{+2}$ block and rely on a depolarizing current from the EPSP of AMPA receptors to have the magnesium block released. Consequently, passing through the NMDA receptors, the influx of calcium ions binds to post-synaptic calmodulin (CaM) molecules containing two binding sites at the C-lobe and N-lobe of CaM. The preference between the two lobes that calcium binds to is dependent on certain conditions and yields differing effects. Calcium binds to 
the C-lobe of CaM based on a rapid and relatively large increase in post-synaptic calcium concentration, which leads to an increase in the surface density and permeability of the AMPA receptors. On the other hand, a slower and smaller increase in post-synaptic calcium concentration causes the calcium to bind to the N-lobe of CaM, resulting in a decrease in the surface density and permeability of the AMPA receptors. As follows, in relation to TMS, a higher frequency may result in a strong removal in the voltage-gated magnesium block leading to a more rapid increase in calcium concentration and LTP. A lower frequency may have a weaker influence on removing the magnesium block yielding a slower increase in calcium concentration resulting in LTD.

A concept where the Hebbian theory is modified to regulate continuous positive feedback can be seen in the Beinenstock-Cooper-Munro (BCM) synapse [83] [84]. Instead of having continuously increasing potentiation or depression as the Hebbian theory would suggest, potentiation or depression is regulated to maintain homeostasis. The BCM model proposes a mechanism where LTP or LTD is encouraged depending on the threshold level of post-synaptic activity. In turn, the threshold level is on a sliding scale and changes to encourage potentiation when activity is low and depression when activity is high.

While this paper only allows for a brief understanding of TMS and the underlying mechanisms at play, it should be noted that TMS does not only affect the local area of treatment, but may induce changes in other areas of the brain [85] [86] as well as alter gene expression patterns [87].

\subsection{Other Stimulation Modalities}

Stimulations excluded from the class of EPA’s may include therapies that apply physical or manipulative pressure and therapies that project sound and stimulate a patient through auditory means.

Sound and music therapy is an auditory stimulation technique that can affect synaptic plasticity and play a role in psychotherapy. Therapeutic techniques can range from listening to music or sounds to singing, playing or writing music in combination with other activities such as movement, meditation or visual aids. Although some studies in music therapy consist of a small sample size or lacks a refined technique or is inconclusive, there is an accumulating trend that has shown auditory stimulation to have positive physiological and neural effects.

Music can stimulate the biological system by manipulating a person's respiration and heart rate, blood pressure, brainwave activity, or emotional state of mind [88]. As a result, music has been show to be of assistance in the treatment of numerous mental health conditions including, but not limited to, autism [89]-[92], dementia and Alzheimer's disease [93]-[99], ADHD [100]-[102], depression [103]-[105], Parkinson's disease [106] [107], schizophrenia [108] [109], PTSD [110] and tinnitus [111] [112]. Music therapy may enhance cognitive functions such as spatial-temporal reasoning in children, memory, and language skills [113]-[116]. Pertaining to ADHD and autism spectrum disorders, interaction with music can have a positive effect on children or patients with learning disabilities through improving motivation, joint attention behaviour, and communicative skills [89] [90] [100]. Addictive impulses may also be decreased through relaxation effects, improving mood or emotion, and increasing in energy levels [117]-[121].

Music also helps in the reduction of pain, anxiety and stress while improving mood, compliance and relaxation. The use of music for the reduction of pain has been researched in hospital and post-operation settings [122]-[124], for pediatric pain [125]-[127], and pain conditions such as labor, chronic, acute, and malignant pain [128]-[130]. However, a systematic review showed minor benefits of music therapy in pain treatment and concluded that the role of music was questionable in its clinical importance [131]. Yet, another review on pediatric pain suggested further research was required and summarized the possible effects of music therapy through three interpretations [125]. The first interpretation being the allowance of sensory stimuli and the reduction of noxious stimuli transferred through the neural gate by means of the gate-control theory of pain. The second interpretation being the limitation of the emotional-affective component of pain due to music therapy causing a decrease in the activity level of the amygdala. Lastly, the third interpretation indicates that music therapy can be a form of distraction, acting as a coping mechanism rather than a pain-relief mechanism.

A study on the release of neurotransmitters and neurohormones due to music therapy revealed that an increase in melatonin serum, plasma norepinephrine and plasma epinephrine was evident after four weeks music therapy sessions with Alzheimer's disease patients [132]. The paper speculated that the increase in norepinephrine and epinephrine could have lead to the increase in melatonin levels due to their role in the synthesis and release of melatonin. In turn, the increase in melatonin may have a hand in influencing relaxation and the mood of the patient. However, a six week post-session follow-up showed that only melatonin levels continued to increase while norepinephrine and epinephrine levels decreased back to baseline values. 
Apart from music therapy, another stimulation module lies in physical pressure, force, and mechanical sensations, which can be applied through whirlpool tubs and airbaths as a form of balneotherapy or through manual and manipulative therapy. Manual and manipulative therapy lies under physical therapy and manual medicine and is typically used for the treatment of chronic pain, musculoskeletal disorders and rehabilitation. Massage therapy has varying evidence on its effectiveness towards chronic, non-malignant pain conditions. A review by Tsao J. (2007) revealed a higher amount of support for the effectiveness of massage therapy in non-specific lower back pain patients. However, other chronic pain conditions such as shoulder pain, headache pain, fibromyalgia, mixed chronic pain, neck pain and carpal tunnel syndrome have a sequentially decreasing amount of effectiveness [133].

Stimulation through massage therapy consists of a large market which can also be translated to mechanical devices and it plays a vital role in the reduction of stress and improvement of the quality of life. A general observation can be made in massage therapy where man-made massage chairs or platforms are significantly less desirable as compared to receiving treatment from a masseuse.

Quite independent of the exact nature of the stimulation, the most effective temporal pattern of stimulation is yet unanswered. Periodic and random temporal patterns have been found to be useful to some degree, but an effective, theoretically and biologically justifiable pattern remains elusive. The normal physiological intrinsic biological dynamics, its properties and utility, will be examined in the following section. After which, a universal temporal pattern for stimulation will be proposed to which the biological system is most responsive, as well as optimal for functional restoration and enhancement.

\section{Fractal Dynamics}

All physiological systems, such as the nervous, metabolic, immune systems, are composed of interacting elements which collectively form a network. One theoretical framework for understanding network behaviour is the discipline of nonlinear dynamics, which takes into account of the nonlinear properties of the constituent elements in the network.

\subsection{Introductory Remarks}

To illustrate the concept "network as dynamical system" more concretely, consider a small network with few elements with varying degrees of sigmoid nonlinearity (Figure 1). By appropriate adjustment of the thresholds and strengths of excitatory $(+)$ and inhibitory $(-)$ connections in network A, the whole network can be approximated with one element containing a single-hump function (B).

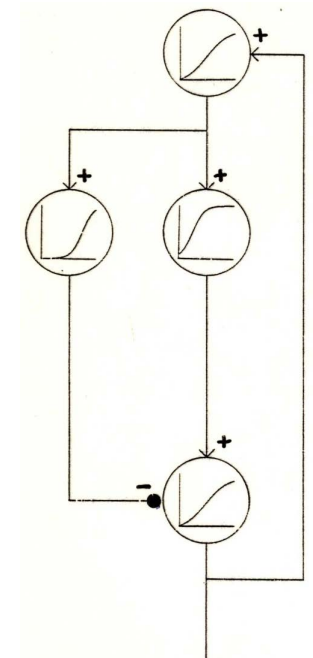

(A)

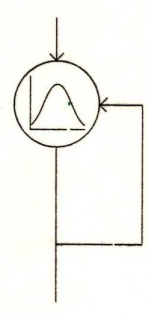

(B)

Figure 1. A small network of elements with varying degrees of sigmoidal nonlinearity (A). Appropriate adjustments to the network connections lead to network B, composed of a single element with an approximated single-hump function. 
The dynamical behaviours of single-hump functions are well known. Now consider a logistic quadratic map with the parameter $0<a<4$, where $\mathrm{y}=\mathrm{f}(\mathrm{x})=\mathrm{ax}(1-\mathrm{x})$. $\mathrm{x}_{\mathrm{n}}$ can be plotted against $\mathrm{x}_{\mathrm{n}+1}$ and $\mathrm{x}$ represents a variable that falls in between 0 and 1 . The range of possible dynamical behaviours can be observed through determining the orbit $\left\{\mathrm{x}_{0}, \mathrm{x}_{1}, \mathrm{x}_{2}, \ldots\right\}$; by changing the network connection strength or parameter, the behaviour can range from periodic motion with different periods to full-blown aperiodic, unpredictable chaos.

These qualitative changes in dynamical behaviors may be captured in a bifurcation diagram (Figure 2), which plots $\mathrm{x}$ at large times against the parameter $a$. As the parameter $a$ is varied, an orderly progression develops from periods $1,2,4,8,16 \ldots$ to infinite period, beyond which chaos sets in, intersperse with an infinite number of periodic windows as the parameter continues to vary. This is the well-known period doubling route to chaos [134] [135].

These dynamics or motions can be characterized by examining the behaviours of these networks or systems when given similar inputs or perturbations. For regular or non-chaotic motion, Figure 3 shows different inputs within the black band that eventually end up in periodic motion or a fixed-point (period 1). In fact, all inputs

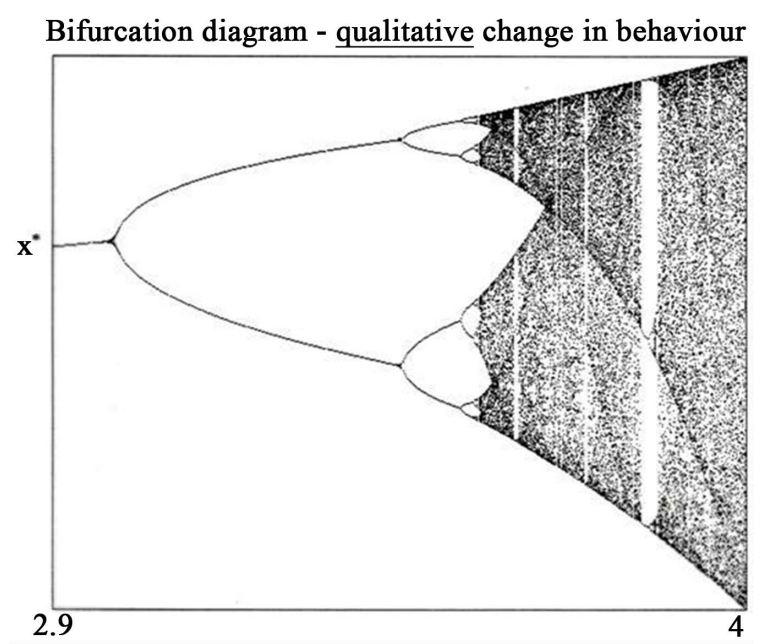

Figure 2. Bifurcation diagram showing the qualitative change in behavior of $\mathrm{x}$ at large times with respect to the change in parameter $a$ within the range of 2.9 to 4 , illustrating the period-doubling route to chaos.

Insensitive to environmental inputs
Exponential convergence of orbits

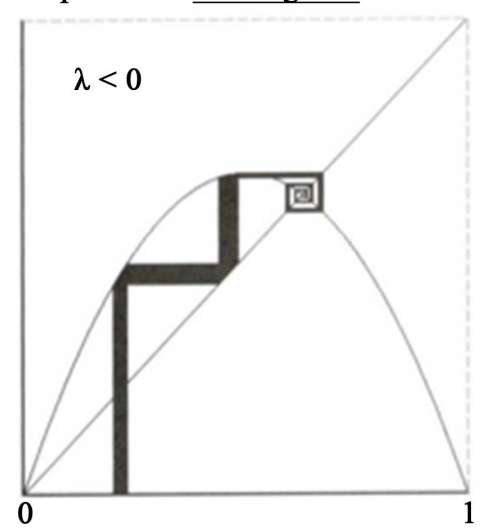

Figure 3. A quadratic map with exponential convergence of orbits with different initial conditions. Different environmental input values entering the network converges to the same periodic points or fixed point [135]. 
converge exponentially towards the fixed point or periodic points, irrespective of what the environmental input to this network. This exponential convergence can be characterized by the Lyapunov exponent $\lambda$ [136], with $\lambda<$ 0 indicating the average rate of convergence. In contrast, when the parameter is such that the network is in chaotic motion, an exponential divergence $(\lambda>0)$ of nearby orbits for similar initial conditions or inputs is evident (Figure 4). This divergence generates very different network responses under very similar input conditions, which is not a desirable property for a biological system.

From a theoretical standpoint, three options exist for the type of network dynamic that is most suitable for biological computation and control (Table 3).

\subsection{Fractal Dynamics in Physiological Systems}

Given these considerations, the fractal multi-scale dynamics would be prevalent in normal biological networks, and diseased systems would exhibit pathological dynamics of periodic and/or chaotic motions. Much evidence is in support of this contention.

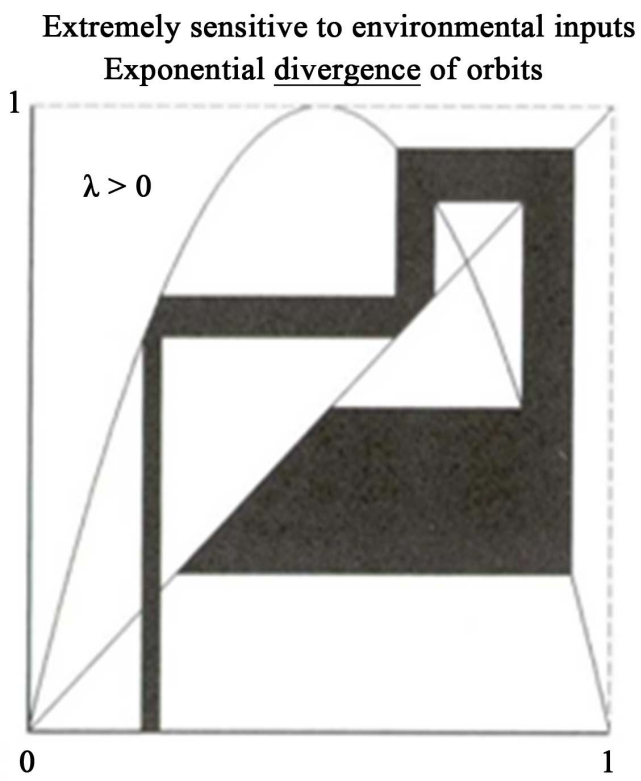

Figure 4. A quadratic map with exponential divergence of orbits with similar initial conditions.

Table 3. Characteristics of three types of network dynamics.

\begin{tabular}{|c|c|c|c|}
\hline & \multicolumn{3}{|c|}{ Network Dynamic } \\
\hline & Regular or Periodic Motion & Chaotic Motion & Motion at the Edge of Chaos \\
\hline $\begin{array}{l}\text { Lyapunov } \\
\text { Exponent }\end{array}$ & $\begin{array}{c}\lambda<0 \\
\text { Exponentially convergent }\end{array}$ & $\begin{array}{c}\lambda>0 \\
\text { Exponentially divergent }\end{array}$ & $\begin{array}{c}\lambda=0 \\
\text { Fractal } \\
\text { Self-similar } \\
\text { Multi-scale or scale-free }\end{array}$ \\
\hline Properties & $\begin{array}{l}\text { Insensitive to differences } \\
\text { in environmental input. } \\
\text { Rapid dissipation of } \\
\text { information from } \\
\text { environment-hence no } \\
\text { dynamic memory. }\end{array}$ & $\begin{array}{l}\text { Exponential divergence of orbits or responses } \\
\text { with small differences in environmental input. } \\
\text { Rapid dissipation of information from } \\
\text { environment—no dynamic memory. }\end{array}$ & $\begin{array}{l}\text { Long-range or power-law correlation. } \\
\text { Motion has no exponential dissipation, } \\
\text { hence long memory. } \\
\text { Sensitive and therefore responsive } \\
\text { to inputs from the environment. } \\
\text { Most compatible with biological } \\
\text { computation and control. }\end{array}$ \\
\hline
\end{tabular}


Patterns of human EEG have been recorded from different scalp regions from a normal subject and patients with different neurological conditions. A general feature is the multi-scale fractal EEG pattern of the normal subject. Patients with different neurological conditions, such as petit mal and grand mal seizures, display highly periodic dynamics [4]. Multiple random spikes were seen in patients with partial epilepsy, yielding a noticeably different pattern from the normal, healthy subject [137].

Several studies have found a decreased or abnormal complexity in the EEG activity of other various mental ailments including depression [138] [139], brain lesions due to stroke [140], schizophrenia [138] [141], and Alzheimer's disease [142] [143]. A reduction in complexity may be an indication of neural activity moving away from a fractal dynamic. A study based on the complexity of EEG activity in stroke patients showed a decrease in fractal dimension for patients with lesions in the left or right hemispheres of the brain during the acute phase of stroke [140]. The lower fractal dimension was more noticeable in the affected area. It was also discovered that a worse clinical recovery of stroke yielded lower fractal dimension values. Analyses of EEG activity in schizophrenic [141] and Alzheimer's diseased [143] patients also showed an increase in complexity among certain regions compared to healthy subjects.

Pathological periodic dynamics manifests itself not only in the CNS, but in the cardiopulmonary system as well, in Cheyne-Stokes breathing, and heart failure [5]. Furthermore, even in patients with myelogenous leukemia, periodic blood cell dynamics were observed to have a cyclic pattern in white blood cell concentration over 250 days as compared to a fractal-like pattern in healthy patients [7] [144].

In addition to the emergence of periodic dynamics $(\lambda<0)$, chaotic dynamics $(\lambda<0)$ can be observed in disease states as well. One paper depicts the heart rate variability of four subjects [6]. Of the four candidates, only the healthy subject exhibits the multi-scale fractal variations $(\lambda=0)$. Highly periodic motions $(\lambda<0)$ may be seen in two of the subjects in sinus rhythm associated with heart failure. The last subject depicts a patient with atrial fibrillation with an erratic heart rate, illustrating the possibility of the breakdown of normal dynamics (i.e. the dynamics of the healthy subject) into the pathological chaos-like dynamics $(\lambda>0)$. Similar breakdown into chaos can be seen in Huntington's disease as well as in the gait pattern of the elderly [6].

Theoretical considerations and experimental observations all point to the fractal nature of normal physiological dynamics, and a departure from fractal is an indicator of diseased processes. Since fractal dynamics lies between regular or periodic motion and chaos, it is often referred to as dynamics at the edge of chaos. In this regard, the underlying aim of all therapeutic interventions, physical, pharmacological, surgical or otherwise, is to restore the network back to fractal motion, at the edge of chaos, away from highly mechanical periodic, or highly unpredictable chaotic processes.

\subsection{Fractal for the Optimization of Stimulation Therapy}

The nature of the dynamics of the therapeutic stimulus to which the system is responsive and optimal for restoring and nurturing a pathological system back to health resides in the fact that persistent scale-free fractal dynamics is the normal mode of operation for a functioning biological system.

Since periodicity is the common temporal feature that underlies these cases, one may conclude that the non-fractal periodic external stimulus pattern can induce pathological, non-fractal seizure dynamics in biological systems. To elaborate, a periodic pattern of stimulation, by virtue of the plasticity of biological systems, may actually encourage the establishment of new, or entrenchment of existing pathological periodic dynamics, or both, thus defeating the intention of the therapeutic approach. On the other hand, by subjecting a patient with an existing periodic pathology to non-periodic fractal stimulation, the stimulation will encourage a fractal dynamic in the patient through Hebbian mechanisms. These considerations strongly argue against the use of periodic patterns as optimal for therapeutic intervention.

However, it is undeniable that the conventional periodic stimulus pattern has been successful in many clinical settings. This success may be attributed to the fact that when a constant sustained periodic stimulation is employed, the sustained nature of the stimulation, in the context of a dynamical system, actually serves as a parameter. As discussed earlier, parameter change does induce bifurcations, and if the bifurcation happens to bring about a desirable (fractal) dynamical state, then the periodic stimulus pattern would achieve its goal. A major risk, however, is the inadvertent consolidation of the existing pathological periodicity discussed above, a risk that is absent when fractal stimulation is deployed.

In addition, periodic stimulation in TENS for relief of chronic pain has been observed to slowly lose its efficacy as the treatment session progresses [20] [21]. This may be the result of habituation of the CNS to the mo- 
notone periodic pattern for activation. The use of a constant, periodic frequency may also dampen the subject's reaction to the voltage or current pulse, resulting in a lower therapeutic effect over a period of time. Furthermore, for specified parameter settings, a stimulation modality may not have the same effectiveness for every patient or scenario. Thus, a solution could be to optimally increase the variability of the stimulus frequency rather than finding and implementing a certain frequency that may lead back to a periodic dynamic. A fractal pattern would then be an effective and natural way to implement an increase in variability.

Past studies have shown evidence for certain stimulus patterns leading to pathological dynamics. For instance, epileptic seizures have been reported to be induced by periodic patterns of stimulation. They were observed in the use of strobe lights (photic-induced seizure) at certain frequencies and in clinical applications of TMS [143] [145]. Intraoperative electrocortical stimulations, used to help monitor and generate functional responses during tumor surgeries, are also well-known to have the adverse effects of causing epileptic seizures during operation [147]. Current intraoperative electrocortical stimulations use a periodic pulsed rhythm to stimulate the brain. These observations underscore the risks of periodic stimulus in either inducing or reinforcing pathological periodic dynamics.

Given the undesirability of periodicity as a stimulus pattern, we are left with randomness, deterministic chaos and fractals as options. A clue to the optimal pattern to which our own dynamics is most sympathetic is found in music. Music has been central to all cultures, and a common observation in most music is its fractal, multi-scale temporal character. This characteristic is in stark contrast to our aversion to random noise (similar to chaos, though strictly not equivalent) which is sometimes observed in some contemporary music. Recently, it has been shown that fractal tones can be an effective tool for treating tinnitus. It was also found that the use of fractal tones was subjectively preferred over more periodic, steady-state-like sounds [148]-[150]. Sudden variations in amplitude, representative of a random system, were counterproductive as well.

In regard to spatial fractal patterns, it has been demonstrated that a single electrode with fractal geometry was optimal in the delivery of current as compared to the non-fractal counterpart [151]. By extension, in conjunction with fractal temporal patterns, electrodes with a fractal geometry, together with a spatially fractal pattern of placement of these electrodes over a body region, may provide optimal therapeutic effect, particularly with spatially distributed networks like the CNS.

It may be deduced that the dynamic required is the dynamic at which the body is physiologically healthy. It is the fractal dynamics that is both sensitive and responsive, with which the body is most in tune and which exhibits long-range correlation or memory. At the same time, by moving away from periodicity, the physiological system avoids the possible pitfalls of central habituation and further consolidation of existing pathological dynamics.

\section{Implementation and Possible Configurations}

The fractal sequence may be obtained through conventional mathematical methods: iterated function systems, L-systems, escape-time fractals, random fractals, or finite subdivision rule [152]-[156]. The fractal sequence may also be obtained through using the physiological measurements of a healthy biological system. Sequentially, the acquired fractal sequence is scaled to the desired magnitude relative to the appropriate output range of the stimulation device. One embodiment uses the inter-beat or RR interval of a healthy human subject, which has fractal variability. RR intervals are the time intervals between each heartbeat starting from the beginning of one QRS complex to the consecutive QRS complex. To minimize error, intervals between the peak R waves of each heartbeat can be measured through an electrocardiogram (ECG). By recording and appropriately scaling the sequential RR intervals, a fractal pattern that can be applied to therapeutic stimulation is obtained.

The implementation of a fractal pattern for stimulation therapies must be taken on an individual or situational basis. The adjustable parameters that are selected to contain a fractal sequence should be relevant to producing an optimal treatment based on the principle mechanisms of the stimulation modality. Many physiological mechanisms operate on the basis of having a threshold limitation where a stimulus may not have the desired effect until it reaches a certain threshold. Therefore, an understanding of the therapeutic methodology and underlying principles would be necessary to experiment with fractal stimulation. Figure 5 shows possible configurations where a fractal system can be applied and how it should affect the physiology of the subjected patient.

As an example, optimizing a TENS device would entail stronger analgesic effects, faster healing times, longer lasting effects post treatment, and the prevention of habituation. In modulation mode TENS, the frequency, 


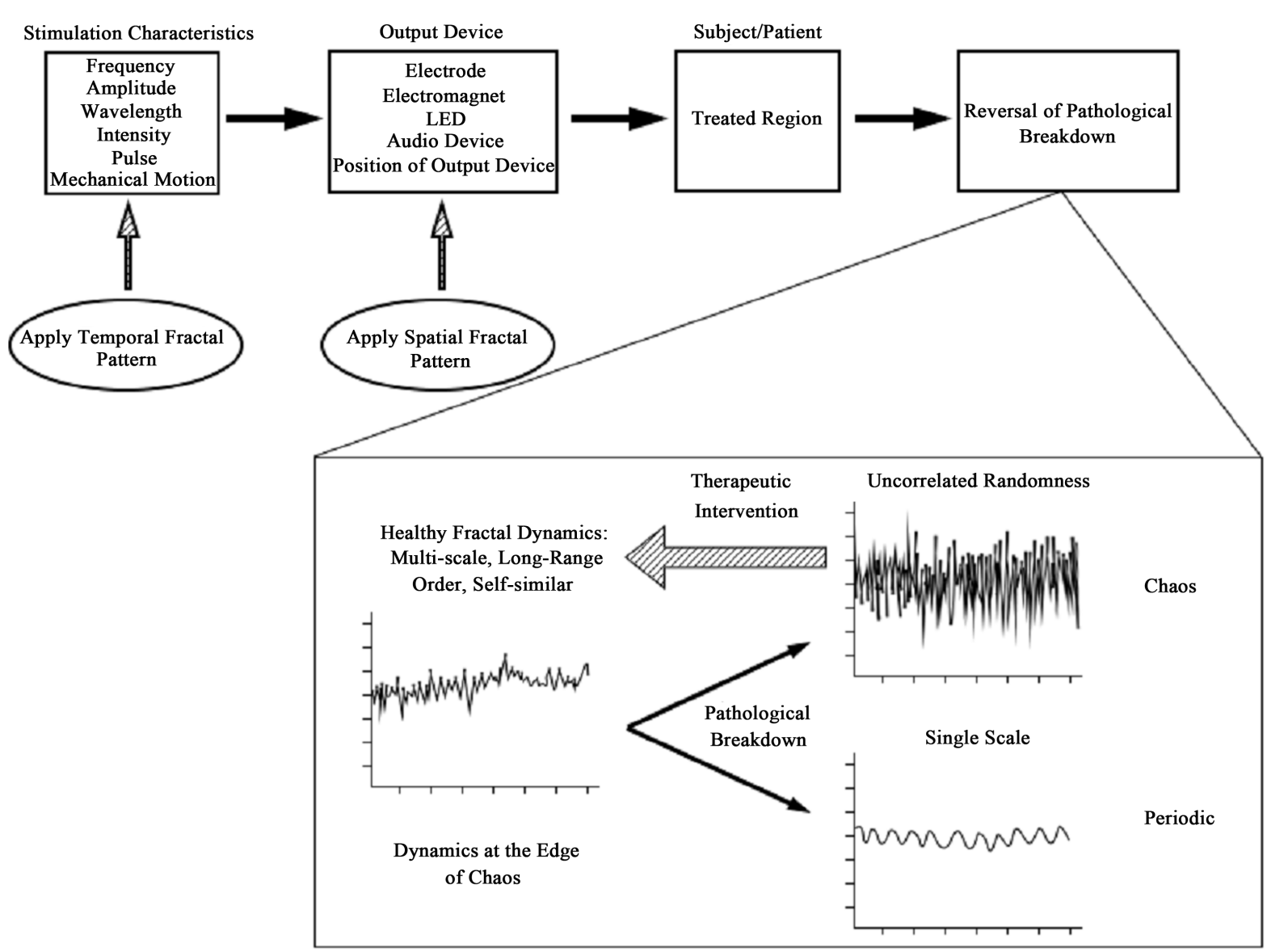

Figure 5. A schematic showing the sequence of procedures that eventually leads to a reversal of the pathological breakdown [157].

intensity or pulse duration can be modified to deliver a fractal patterned current. Moving away from periodicity would likely reduce the tolerance of the patient towards the treatment. A higher variability in frequency and possibly in other parameters could also lead to the activation of more healing and analgesic mechanisms. It should be noted that the frequency should only vary within its appropriate therapeutic range. If the intensity is changed to hold a fractal pattern, a maximum and minimum threshold should be set to prevent painful, noxious stimuli or intensities that have no effect. Other parameters that may be considered are the electrode placement and electrode shape, however, in TENS therapy, the placement of electrodes are usually conformed to certain regions based on the ailment being treated.

Fractal stimulation can be similarly applied to other TENS-like modalities in the same fashion. In certain electrical stimulation modalities which use microcurrent, the physiological principle is based on a cellular level where cellular activity is likely to follow a more complex, fractal dynamic rather than a simple periodic one. As follows, a fractal stimulus may optimize or be more effective in improving cellular functions such as ATP production, protein synthesis, oxygenation, ion exchange and nutrient absorption.

Similar to the TENS module, the application of fractal patterns to thermal therapy can be a way to limit habituation and increase effectiveness. Thermal modalities applied through conversion (ultrasound, diathermy, etc.) may be modified by varying their frequency, intensity or pulse. Modalities using convection (fluidotherapy, hydrotherapy) can vary the strength, pulse, temperature, or the placement where air or water is applied in a fractal manner. Thermal modalities using conduction (hydrocollator packs, wax therapy, etc.) can also implement a fractal pattern in through their method of placement or geometrical shape. A method where the thermal substance is applied in a temporal fractal pattern on the treated area is likely too troublesome for inexpensive solutions such as heat packs.

In music therapy, many forms of music are inherently fractal where self-similar patterns arise through the 
verses and chorus. For instance, a typical song may have a basic, repetitive bass or rhythm, but the melody holds self-similar variation which separates itself from a repetitive structure and increases its complexity. Fractal tones have been shown to be effective in treating tinnitus in comparison to periodic or random-like sounds [147]-[149]. In the same sense, fractal tones could be expanded and used in other sound therapies.

The use of vibration and pressure in physical therapy can be enhanced by applying a fractal pattern. Like many forms of music, professional massages are inherently fractal. A massage chair for instance follows that of a cyclic, repetitive pattern, whereas a professional massage tends to have a fractal entity as no two strokes have the exact same pressure and masseuses tend to vary their techniques, positioning and rhythm. Consequently, common sense should indicate that highly periodic or random massage techniques would substantially be less comfortable. In this manner, modifying a massage chair to be spatiotemporally fractal should increase the likelihood of a more effective and enjoyable treatment. The vibrational frequency, the intensity of the pressure, placement or shape of the applied pressure and the timing of pressure or vibration can all be adjusted to follow that of a fractal pattern.

\section{Conclusion}

The central question we address in the present review is what stimulus parameters are optimal to effect a change or modification in the biological network in question towards recovery. Since healthy physiological dynamics is inherently fractal, viz. self-similar, scale-invariant and non-periodic, to encourage the restoration to a healthy dynamical state via Hebbian mechanisms, we argue that the optimal stimulus pattern should likewise be fractal in character. As a corollary, through Hebbian mechanisms, the conventional periodic stimulus patterns may run the risk of inducing or further entrenching the existing pathological periodic dynamics, as evidenced above, and thus impeding sustainable recovery.

\section{References}

[1] Watson, T. (2010) Key Concepts with Electrophysical Agents. Physical Therapy Reviews, 15, 351-359. http://dx.doi.org/10.1179/1743288X10Y.0000000009

[2] Nadler, S.F., Weingand, K. and Kruse, R.J. (2004) The Physiologic Basis and Clinical Applications of Cryotherapy and Thermotherapy for the Pain Practitioner. Pain Physician, 7, 395-399.

[3] Panas, E. and Ninni, V. (2010) The Distribution of London Metal Exchange Prices: A Test of the Fractal Market Hypothesis. European Research Studies, 13, 193-210.

[4] Robinson, P.A., Rennie, C.J. and Rowe, D.L. (2002) Dynamics of Large-Scale Brain Activity in Normal Arousal States and Epileptic Seizures. Physical Review E, 65, Article ID: 041924. http://dx.doi.org/10.1103/PhysRevE.65.041924

[5] Findley, L.J., Blackburn, M.R., Goldberger, A.L. and Madnell, A.J. (1984) Apneas and Oscillation of Cardiac Ectopy in Cheyne-Stokes Breathing during Sleep. American Review of Respiratory Disease, 130, 937-939.

[6] Goldberger, A.L., Amaral, L.A., Hausdorff, J.M., et al. (2002) Fractal Dynamics in Physiology: Alterations with Disease and Aging. Proceedings of the National Academy of Sciences of the United States of America, 99, 2466-2472. http://dx.doi.org/10.1073/pnas.012579499

[7] Goldberger, A.L. (1997) Fractal Variability versus Pathologic Periodicity: Complexity Loss and Stereotypy in Disease. Perspectives in Biology and Medicine, 40, 543-561.

[8] Robinson, A.J. and Snyder-Mackler, L. (1995) Clinical Electrophysiology: Electrotherapy and Electrophysiological testing. 2nd Edition, Williams \& Wilkins, Philadelphia.

[9] Melzack, R. and Wall, P. (1965) Pain Mechanisms: A New Theory. Science, 150, 971-979. http://dx.doi.org/10.1126/science.150.3699.971

[10] Ellrich, J. and Lamp, S. (2005) Peripheral Nerve Stimulation Inhibits Nociceptive Processing: An Electrophysiological Study in Healthy Volunteers. Neuromodulation, 8, 225-232. http://dx.doi.org/10.1111/j.1525-1403.2005.00029.x

[11] Sluka, K.A. and Walsh, D. (2003) Transcutaneous Electrical Nerve Stimulation: Basic Science Mechanisms and Clinical Effectiveness. Journal of Pain, 4, 109-121. http://dx.doi.org/10.1054/jpai.2003.434

[12] Hughes, G.S., Lichstein, P.R., Whitlock, D. and Harker, C. (1984) Response of Plasma Beta-Endorphins to Transcutaneous Electrical Nerve Stimulation in Healthy Subjects. Physical Therapy, 64, 1062-1066.

[13] Salar, G., Job, I., Mingrino, S., Bosio, A. and Trabucchi, M. (1981) Effect of Transcutaneous Electrotherapy on CSF $\beta$ Endorphin Content in Patients without Pain Problems. Pain, 10, 169-172. http://dx.doi.org/10.1016/0304-3959(81)90192-5 
[14] Han, J.S., Chen, X.H., Sun, S.L, et al. (1991) Effect of Low and High Frequency TENS on Met-Enkephalin-Arg-Phe and Dynorphin A Immunoreactivity in Human Lumbar CSF. Pain, 47, 295-298. http://dx.doi.org/10.1016/0304-3959(91)90218-M

[15] Sluka, K.A. (2008) The Neurobiology of Pain and Foundations for Electrical Stimulation. In: Robinson, A.J. and SnyderMackler, L., Eds., Clinical Electrophysiology, Lippincott Williams \& Wilkins, Philadelphia, 107-149.

[16] Sluka, K.A., Deacon, M., Stibal, A., Strissel, S. and Terpstra, T. (1999) Spinal Blockade of Opioid Receptors Prevents the Analgesia Produced by TENS in Arthritic Rats. Journal of Pharmacology and Experimental Therapeutics, 289, 840-846.

[17] Kalra, A., Urban, M.O. and Sluka, K.A. (2001) Blockade of Opioid Receptors in Rostral Ventral Medulla Prevents Antihyperalgesia Produced by Transcutaneous Electrical Nerve Stimulation (TENS). Journal of Pharmacology and Experimental Therapeutics, 298, 257-263.

[18] Sluka, K.A. and Chandran, P. (2002) Enhanced Reduction in Hyperalgesia by Combined Administration of Clonidine and TENS. Pain, 100, 183-190. http://dx.doi.org/10.1016/S0304-3959(02)00294-4

[19] Watson, T. (2010) Transcutaneous Electrical Nerve Stimulation (TENS). http://www.electrotherapy.org/modality/transcutaneous-electrical-nerve-stimulation-tens

[20] DeSantana, J.M., Walsh, D.M., Vance, C., Rakel, B.A. and Sluka, K.A. (2008) Effectiveness of Transcutaneous Electrical Nerve Stimulation for Treatment of Hyperalgesia and Pain. Current Rheumatology Reports, 10, 492-499. http://dx.doi.org/10.1007/s11926-008-0080-z

[21] Liebano, R.E., Rakel, B., Vance, C.G., Walsh, D.M. and Sluka, K.A. (2011) An Investigation of the Development of Analgesic Tolerance to TENS in Humans. Pain, 152, 335-342. http://dx.doi.org/10.1016/j.pain.2010.10.040

[22] Chandran, P. and Sluka, K.A. (2003) Development of Opioid Tolerance with Repeated Transcutaneous Electrical Nerve Stimulation Administration. Pain, 102, 195-201. http://dx.doi.org/10.1016/s0304-3959(02)00381-0

[23] DeSantana, J.M., Santana-Filho, V.J. and Sluka KA. (2008) Modulation between High- and Low-Frequency Transcutaneous Electric Nerve Stimulation Delays the Development of Analgesic Tolerance in Arthritic Rats. Archives of Physical Medicine and Rehabilitation, 89, 754-760. http://dx.doi.org/10.1016/j.apmr.2007.11.027

[24] Pomeranz, B. and Niznick, G. (1987) Codetron, a New Electrotherapy Device Overcomes the Habituation Problems of Conventional TENS Devices. American Journal of Electromedicine, First Quarter, 22-26.

[25] Hingne, P.M. and Sluka, K.A. (2008) Blockade of NMDA Receptors Prevents Analgesic Tolerance to Repeated Transcutaneous Electrical Nerve Stimulation (TENS) in Rats. Journal of Pain, 9, 217-225. http://dx.doi.org/10.1016/j.jpain.2007.10.010

[26] DeSantana, J.M., da Silva, L.F. and Sluka, K.A. (2010) Cholecystokinin Receptors Mediate Tolerance to the Analgesic Effect of TENS in Arthritic Rats. Pain, 148, 84-93. http://dx.doi.org/10.1016/j.pain.2009.10.011

[27] Cheng, N., Van Hoof, H., Bockx, E., et al. (1982) The Effects of Electric Currents on ATP Generation, Protein Synthesis, and Membrane Transport of Rat Skin. Clinical Orthopaedics and Related Research, 171, 264-272.

[28] Okihana, H. and Shimomura, Y. (1988) Effect of Direct Current on Cultured Growth Cartilage Cells in Vitro. Journal of Orthopaedic Research, 6, 690-694. http://dx.doi.org/10.1002/jor.1100060511

[29] Davis, P. (1992) Microcurrent. A Modern Healthcare Modality. Rehab and Therapy Products Review, 10, 62-66.

[30] Algafly, A.A. and George, K.P. (2007) The Effect of Cryotherapy on Nerve Conduction Velocity, Pain Threshold and Pain Tolerance. British Journal of Sports Medicine, 41, 365-369. http://dx.doi.org/10.1136/bjsm.2006.031237

[31] Reid, G., Babes, A. and Pluteanu, F.J. (2002) A Cold- and Menthol-Activated Current in Rat Dorsal Root Ganglion Neurones: Properties and Role in Cold Transduction. The Journal of Physiology, 545, 595-614. http://dx.doi.org/10.1113/jphysiol.2002.024331

[32] On, A.Y., Colakoglu, Z., Hepguler, S. and Aksit, R. (1997) Local Heat Effect on Sympathetic Skin Responses after Pain of Electrical Stimulus. Archives of Physical Medicine and Rehabilitation, 78, 1196-1199. http://dx.doi.org/10.1016/S0003-9993(97)90331-2

[33] Martinez, D.A. (2010) Therapeutic Ultrasound: A Review of the Literature. http://www.chiroaccess.com/Articles/Therapeutic-Ultrasound-A-Review-of-the-Literature.aspx?id=0000210

[34] Robertson, V.J. and Baker, K.G. (2001) A Review of Therapeutic Ultrasound: Effectiveness Studies. Physical Therapy, 81, 1339-1350.

[35] Baker, K.G., Robertson, V.J. and Duck, F.A. (2001) A Review of Therapeutic Ultrasound: Biophysical Effects. Physical Therapy, 81, 1351-1358.

[36] Widdess-Walsh, P., Kellinghaus, C., Bösebeck, F., Schuele, S. and Loddenkemper, T. (2010) Efficacy of Electrical Brain Stimulation in Epilepsy. Therapy, 7, 481-496. http://dx.doi.org/10.2217/thy.10.53 
[37] Geschwind, N. (1965) Disconnexion Syndromes in Animals and Man. I. Brain, 88, 237-294. http://dx.doi.org/10.1093/brain/88.2.237

[38] Geschwind, N. (1965) Disconnexion syndromes in Animals and Man. II. Brain, 88, 585-644. http://dx.doi.org/10.1093/brain/88.3.585

[39] Bachman, P. and Cannon, T.D. (2005) Cognitive and Neuroscience Aspects of Thought Disorder. In: Holyoak, K.J. and Morrison, R.G., Eds., The Cambridge Handbook of Thinking and Reasoning, Cambridge University Press, New York, 493-526.

[40] Buckner, R.L., Andrews-Hanna, J.R. and Schacter, D.L. (2008) The Brain’s Default Network: Anatomy, Function, and Relevance to Disease. Annals of the New York Academy of Sciences, 1124, 1-38. http://dx.doi.org/10.1196/annals.1440.011

[41] Catani, M. and Ffytche, D.H. (2005) The Rises and Falls of Disconnection Syndromes. Brain, 128, 2224-2239. http://dx.doi.org/10.1093/brain/awh622

[42] Friston, K.J. and Frith, C.D. (1995) Developmental Disruptions in Neural Connectivity in the Pathophysiology of Schizophrenia. Clinical Neuroscience, 3, 89-97.

[43] Weinberger, D.R., Berman, K.F., Suddath, R. and Torrey, E.F. (1992) Developmental Disruptions in Neural Connectivity in the Pathophysiology of Schizophrenia. American Journal of Psychiatry, 149, 890-897.

[44] Baker, J.T., Holmes, A.J., Masters, G., et al. (2013) Disruption of Cortical Association Networks in Schizophrenia and Psychotic Bipolar Disorder. Archives of General Psychiatry, 71, 109-118.

[45] Bullmore, E.T., Frangou, S. and Murray, R.M. (1997) Developmental Disruptions in Neural Connectivity in the Pathophysiology of Schizophrenia. Schizophrenia Research, 28, 143-156. http://dx.doi.org/10.1016/S0920-9964(97)00114-X

[46] Zhang, D., Guo, L., Hu, X., et al. (2012) Increased Cortico-Subcortical Functional Connectivity in Schizophrenia. Brain Imaging and Behavior, 6, 27-35. http://dx.doi.org/10.1007/s11682-011-9138-z

[47] de Kwaasteniet, B., Ruhe, E., Caan, M., et al. (2013) Relation between Structural and Functional Connectivity in Major Depressive Disorder. Biological Psychiatry, 74, 40-47. http://dx.doi.org/10.1016/j.biopsych.2012.12.024

[48] Zhang, J., Wang, J., Wu, Q., et al. (2011) Disrupted Brain Connectivity Networks in Drug-Naive, First-Episode Major Depressive Disorder. Biological Psychiatry, 70, 334-342. http://dx.doi.org/10.1016/j.biopsych.2011.05.018

[49] Ramasubbu, R., Konduru, N., Cortese, F., et al. (2014) Reduced Intrinsic Connectivity of Amygdala in Adults with Major Depressive Disorder. Frontiers in Psychiatry, 19, 17.

[50] Liu, L., Zeng, L., Li, Y., et al. (2012) Altered Cerebellar Functional Connectivity with Intrinsic Connectivity Networks in Adults with Major Depressive Disorder. PLOS ONE, 7, e39516. http://dx.doi.org/10.1371/journal.pone.0039516

[51] Tomasi, D. and Volkow, N.D. (2011) Abnormal Functional Connectivity in Children with Attention-Deficit/Hyperactivity Disorder. Biological Psychiatry, 71, 443-450. http://dx.doi.org/10.1016/j.biopsych.2011.11.003

[52] Cocchi, L., Bramati, I.E., Zalesky, A., et al. (2012) Altered Functional Brain Connectivity in a Non-Clinical Sample of Young Adults with Attention-Deficit/Hyperactivity Disorder. The Journal of Neuroscience, 32, 17753-17761. http://dx.doi.org/10.1523/JNEUROSCI.3272-12.2012

[53] Hulvershorn, L.A., Mennes, M., Castellanos, F.X., et al. (2014) Abnormal Amygdala Functional Connectivity Associated with Emotional Lability in Children with Attention-Deficit/Hyperactivity Disorder. Journal of the American Academy of Child \& Adolescent Psychiatry, 53, 351-361. http://dx.doi.org/10.1016/j.jaac.2013.11.012

[54] Chen, A.C. and Etkin, A. (2013) Hippocampal Network Connectivity and Activation Differentiates Post-Traumatic Stress Disorder from Generalized Anxiety Disorder. Neuropsychopharmacology, 38, 1889-1898. http://dx.doi.org/10.1038/npp.2013.122

[55] Stevensa, J.S., Jovanovica, T. and Fania, N. (2013) Disrupted Amygdala-Prefrontal Functional Connectivity in Civilian Women with Posttraumatic Stress Disorder. Journal of Psychiatric Research, 47, 1469-1478. http://dx.doi.org/10.1016/j.jpsychires.2013.05.031

[56] Sadeh, N., Spielberg, J.M., Warren, S.L., Miller, G.A. and Wendy Heller, W. (2014) Aberrant Neural Connectivity During Emotional Processing Associated With Posttraumatic Stress. Clinical Psychological Science, Published Online.

[57] Beucke, J.C., Sepulcre, J. and Talukdar, T. (2013) Abnormally High Degree Connectivity of the Orbitofrontal Cortex in Obsessive-Compulsive Disorder. JAMA Psychiatry, 70, 619-629. http://dx.doi.org/10.1001/jamapsychiatry.2013.173

[58] Harrison, B.J., Soriano-Mas, C., Pujol, J., et al. (2009) Altered Corticostriatal Functional Connectivity in ObsessiveCompulsive Disorder. Archives of General Psychiatry, 66, 1189-1200. http://dx.doi.org/10.1001/archgenpsychiatry.2009.152

[59] Stern, E.R., Fitzgerald, K.D., Welsh, R.C., Abelson, J.L. and Taylor, S.F. (2012) Resting-State Functional Connectivity between Fronto-Parietal and Default Mode Networks in Obsessive-Compulsive Disorder. PLoS ONE, 7, e36356. http://dx.doi.org/10.1371/journal.pone.0036356 
[60] Jung, W.H., Kang, D., Kim, E., et al. (2013) Abnormal Corticostriatal-Limbic Functional Connectivity in ObsessiveCompulsive Disorder during Reward Processing and Resting-State. NeuroImage: Clinical, 3, 27-38. http://dx.doi.org/10.1016/j.nicl.2013.06.013

[61] Grady, C.L., Furey, M.L., Pietrini, P., Horwitz, B. and Rapoport, S.I. (2001) Altered Brain Functional Connectivity and Impaired Short-Term Memory in Alzheimer's Disease. Brain, 124, 739-756. http://dx.doi.org/10.1093/brain/124.4.739

[62] Gour, N., Felician, O., Didic, M., et al. (2014) Functional Connectivity Changes Differ in Early and Late-Onset Alzheimer's Disease. Human Brain Mapping, 35, 2978-2994. http://dx.doi.org/10.1002/hbm.22379

[63] Li, R., Wu, X., Chen, K., et al. (2013) Alterations of Directional Connectivity among Resting-State Networks in Alzheimer Disease. American Journal of Neuroradiology, 34, 340-345. http://dx.doi.org/10.3174/ajnr.A3197

[64] Unschuld, P.G., Joel, S.E., Liu, X., et al. (2012) Impaired Cortico-Striatal Functional Connectivity in Prodromal Huntington's Disease. Neuroscience Letters, 514, 204-209. http://dx.doi.org/10.1016/j.neulet.2012.02.095

[65] Dumas, E.M., van den Bogaard, S.J., Hart, E.P., et al. (2013) Reduced Functional Brain Connectivity Prior to and after Disease Onset in Huntington's Disease. NeuroImage: Clinical, 2, 377-384. http://dx.doi.org/10.1016/j.nicl.2013.03.001

[66] Werner, C.J., Dogan, I. and Saß, C. (2014) Altered Resting-State Connectivity in Huntington’s Disease. Human Brain Mapping, 35, 2582-2593. http://dx.doi.org/10.1002/hbm.22351

[67] Sharman, M., Valabregue, R., Perlbarg, V., et al. (2013) Parkinson’s Disease Patients Show Reduced Cortical-Subcortical Sensorimotor Connectivity. Movement Disorders, 4, 447-454. http://dx.doi.org/10.1002/mds.25255

[68] Dubbelinka, K.T.E.O., Stoffersa, D., Deijenb, J.B., et al. (2013) Resting-State Functional Connectivity as a Marker of Disease Progression in Parkinson's Disease: A Longitudinal MEG Study. NeuroImage: Clinical, 2, 612-619. http://dx.doi.org/10.1016/j.nicl.2013.04.003

[69] Palomara, F.J., Condea, V., Carrilloa, F., et al. (2013) Parieto-Motor Functional Connectivity Is Impaired in Parkinson’s Disease. Brain Stimulation, 6, 147-154. http://dx.doi.org/10.1016/j.brs.2012.03.017

[70] Yu, R., Liu, B., Wang, L., Chen, J. and Liu, X. (2013) Correction: Enhanced Functional Connectivity between Putamen and Supplementary Motor Area in Parkinson’s Disease Patients. PLoS ONE, 8, e59717. http://dx.doi.org/10.1371/journal.pone.0059717

[71] Fishman, I., Keown, C.L., Lincoln, A.J., Pineda, J.A. and Müller, R. (2014) Atypical Cross Talk between Mentalizing and Mirror Neuron Networks in Autism Spectrum Disorder. JAMA Psychiatry, 71, 751-760. http://dx.doi.org/10.1001/jamapsychiatry.2014.83

[72] Nair, A., Treiber, J.M., Shukla, D.K., Shih, P. and Müller, R.A. (2013) Impaired Thalamocortical Connectivity in Autism Spectrum Disorder: A Study of Functional and Anatomical Connectivity. Brain, 136, 1942-1955. http://dx.doi.org/10.1093/brain/awt079

[73] Pollonini, L., Patidar, U., Situ, N., et al. (2010) Functional Connectivity Networks in the Autistic and Healthy Brain Assessed Using Granger Causality. Annual International Conference of the IEEE Engineering in Medicine and Biology Society. IEEE Engineering in Medicine and Biology Society. Annual Conference, 2010, 1730-1733.

[74] Kleinhans, N.M., Richards, T., Sterling, L., et al. (2008) Abnormal Functional Connectivity in Autism Spectrum Disorders during Face Processing. Brain, 131, 1000-1012. http://dx.doi.org/10.1093/brain/awm334

[75] Huang, Z., Liang, P., Jia, X., et al. (2012) Abnormal Amygdala Connectivity in Patients with Primary Insomnia: Evidence from Resting State fMRI. European Journal of Radiology, 81, 1288-1295. http://dx.doi.org/10.1016/j.ejrad.2011.03.029

[76] Killgore, W.D., Schwab, Z.J., Kipman, M., Deldonno, S.R. and Weber, M. (2013) Insomnia-Related Complaints Correlate with Functional Connectivity between Sensory-Motor Regions. Neuroreport, 24, 233-240. http://dx.doi.org/10.1097/WNR.0b013e32835edbdd

[77] Hebb, D.O. (1949) The Organization of Behavior. Wiley \& Sons, New York.

[78] Thickbroom, G.W. (2007) Transcranial Magnetic Stimulation and Synaptic Plasticity: Experimental Framework and Human Models. Experimental Brain Research, 180, 583-593. http://dx.doi.org/10.1007/s00221-007-0991-3

[79] Malenka, R.C. and Nicoll, R.A. (1999) Long-Term Potentiation-A Decade of Progress? Science, 285, $1870-1874$. http://dx.doi.org/10.1126/science.285.5435.1870

[80] Collingridge, G.L. (2003) The Induction of N-Methyl-D-Aspartate Receptor-Dependent Long-Term Potentiation. Philosophical Transactions of the Royal Society of London. Series B, Biological Sciences, 358, 635-641. http://dx.doi.org/10.1098/rstb.2002.1241

[81] Bliss, T.V.P., Collingridge, G.L. and Morris, R.G.M. (2003) Long-Term Potentiation: Enhancing Neuroscience for 30 Years. Philos Philosophical Transactions of the Royal Society of London. Series B, Biological Sciences, 358, 607-611.

[82] Malenka, R.C. and Bear, M.F. (2004) LTP and LTD: An Embarrassment of Riches. Neuron, 44, 5-21. http://dx.doi.org/10.1016/j.neuron.2004.09.012 
[83] Bienenstock, E.L., Cooper, L.N. and Munro, P.W. (1982) Theory for the Development of Neuron Selectivity: Orientation Specificity and Binocular Interaction in Visual Cortex. Journal of Neuroscience, 2, 32-48.

[84] Bear, M.F. (2003) Bidirectional Synaptic Plasticity: From Theory to Reality. Philosophical Transactions of the Royal Society of London. Series B, Biological Sciences, 358, 649-655. http://dx.doi.org/10.1098/rstb.2002.1255

[85] Fox, P., Ingham, R. and George, M.S. (1997) Imaging Human Intra-Cerebral Connectivity by PET during TMS. Neuroreport, 8, 2787-2791. http://dx.doi.org/10.1097/00001756-199708180-00027

[86] Strafella, A.P., Paus, T., Barrett, J. and Dagher, A. (2001) Repetitive Transcranial Magnetic Stimulation of the Human Prefrontal Cortex Induces Dopamine Release in the Caudate Nucleus. Journal of Neuroscience, 21, RC1571-RC1574.

[87] Ji, R.R., Schlaepfer, T.E., Aizenman, C.D., et al. (1998) Repetitive Transcranial Magnetic Stimulation Activates Specific Regions in Rat Brain. Proceedings of the National Academy of Sciences of the United States of America, 95, 15635-15640. http://dx.doi.org/10.1073/pnas.95.26.15635

[88] Knight, W.E. and Rickard, N.S. (2001) Relaxing Music Prevents Stress-Induced Increases in Subjective Anxiety, Systolic Blood Pressure, and Heart Rate in Healthy Males and Females. Journal of Music Therapy, 38, 254-272. http://dx.doi.org/10.1093/jmt/38.4.254

[89] Kim, J., Wigram, T. and Gold, C. (2009) Emotional, Motivational and Interpersonal Responsiveness of Children with Autism in Improvisational Music Therapy. SAGE Publications and The National Autistic Society, 13, 389-409.

[90] Kim, J., Wigram, T. and Gold, C. (2008) The Effects of Improvisational Music Therapy on Joint Attention Behaviours in Autistic Children: A Randomized Controlled Study. Journal of Autism and Developmental Disorders, 38, 17581766. http://dx.doi.org/10.1007/s10803-008-0566-6

[91] Gold, C., Wigram, T. and Elefant, C. (2006) Music Therapy for Autistic Spectrum Disorder (Review). The Cochrane Database of Systematic Reviews, 19, Article ID: CD004381. http://dx.doi.org/10.1002/14651858.CD004381.pub2

[92] Whipple, J. (2004) Music in Intervention for Children and Adolescents with Autism: A Meta-Analysis. Journal of Music Therapy, 41, 90-106. http://dx.doi.org/10.1093/jmt/41.2.90

[93] Ziv, N., Granot, A., Hai, S., Dassa, A. and Haimov, I. (2007) The Effect of Background Stimulative Music on Behavior in Alzheimer's Patients. Journal of Music Therapy, 44, 329-343. http://dx.doi.org/10.1093/jmt/44.4.329

[94] Fukui, H., Arai, A. and Toyoshima, K. (2012) Efficacy of Music Therapy in Treatment for the Patients with Alzheimer’s Disease. International Journal of Alzheimer's Disease, 2012, Article ID: 531646. http://dx.doi.org/10.1155/2012/531646

[95] Chavin, M. (2002) Music as Communication. Alzheimer's Care Quarterly, 3, 145-156.

[96] Foster, N.A. and Valentine, E.R. (2001) The Effect of Auditory Stimulation on Autobiographical Recall in Dementia. Experimental Aging Research, 27, 215-228. http://dx.doi.org/10.1080/036107301300208664

[97] Sherratt, K., Thornton, A. and Hatton, C. (2004) Music Interventions for People with Dementia. A Review of Die Literature. Aging \& Mental Health, 8, 3-12. http://dx.doi.org/10.1080/13607860310001613275

[98] Thompson, R.G., Moulin, C.J.A., Hayre, S. and Jones, R.W. (2005) Music Enhances Category Fluency in Healthy Older Adults and Alzheimer's Disease Patients. Experimental Aging Research, 31, 91-99. http://dx.doi.org/10.1080/03610730590882819

[99] Simmons-SternAndrew, N.R., Budson, A.E. and Brandon A.A. (2010) Music as a Memory Enhancer in Patients with Alzheimer’s Disease. Neuropsychologia, 48, 3164-3167. http://dx.doi.org/10.1016/j.neuropsychologia.2010.04.033

[100] Jackson, N.A. (2003) A Survey of Music Therapy Methods and Their Role in the Treatment of Early Elementary School Children with ADHD. Journal of Music Therapy, 40, 302-323. http://dx.doi.org/10.1093/jmt/40.4.302

[101] Rickson, D.J. (2006) Instructional and Improvisational Models of Music Therapy with Adolescents Who Have Attention Deficit Hyperactivity Disorder (ADHD): A Comparison of the Effects on Motor Impulsivity. Journal of Music Therapy, 43, 39-62. http://dx.doi.org/10.1093/jmt/43.1.39

[102] Cripe, F.F. (1986) Rock Music as Therapy for Children with Attention Deficit Disorder: An Exploratory Study. Journal of Music Therapy, 23, 30-37. http://dx.doi.org/10.1093/jmt/23.1.30

[103] Chou, M.H. and Lin, M.F. (2006) Exploring the Listening Experiences during Guided Imagery and Music Therapy of Outpatients with Depression. Journal of Nursing Research, 14, 93-102. http://dx.doi.org/10.1097/01.JNR.0000387567.41941.14

[104] Maratos, A.S., Gold, C., Wang, X., Crawford, M.J. (2008) Music Therapy for Depression. Cochrane Database of Systematic Reviews, 1, Article ID: CD004517. http://dx.doi.org/10.1002/14651858.CD004517.pub2

[105] Hendricks, C.B. (2001) A Study of the Use of Music Therapy Techniques in a Group for the Treatment of Adolescent Depression. Dissertation Abstracts International, 62, UMI No. AAT3005267.

[106] Thaut, M.H., McIntosh, G.C., Rice, R.R., et al. (1996) Rhythmic Auditory Stimulation in Gait Training for Parkinson’s Disease Patients. Movement Disorders, 11, 193-200. http://dx.doi.org/10.1002/mds.870110213 
[107] Pacchetti, C., Mancini, F., Aglieri, R., et al. (2000) Active Music Therapy in Parkinson’s Disease: An Integrative Method for Motor and Emotional Rehabilitation. Psychosomatic Medicine, 62, 386-393. http://dx.doi.org/10.1097/00006842-200005000-00012

[108] Gold, C., Heldal, T.O., Dahle, T. and Wigram, T. (2005) Music Therapy for Schizophrenia or Schizophrenia-Like Illnesses. The Cochrane Database of Systematic Reviews, 2, Article ID: CD004025. http://dx.doi.org/10.1002/14651858.CD004025.pub2

[109] Mössler, K., Chen, X., Heldal, T.O. and Gold, C. (2011) Music Therapy for People with Schizophrenia and Schizophrenia-Like Disorders. The Cochrane Database of Systematic Reviews, 12, Article ID: CD004025. http://dx.doi.org/10.1002/14651858.CD004025.pub3

[110] Moore, K. and Sena, M.M. (2013) A Systematic Review on the Neural Effects of Music on Emotion Regulation: Implications for Music Therapy. Practice Journal of Music Therapy, 50, 198-242. http://dx.doi.org/10.1093/jmt/50.3.198

[111] Stracke, H., Okamoto, H. and Christo, P. (2010) Customized Notched Music Training Reduces Tinnitus Loudness. Communicative \& Integrative Biology, 3, 274-277. http://dx.doi.org/10.4161/cib.3.3.11558

[112] Grapp, M., Hutter, E., Argstatter, H., Plinkert, P.K. and Bolay, H.V. (2013) Music Therapy as an Early Intervention to Prevent Chronification of Tinnitus. International Journal of Clinical and Experimental Medicine, 6, 589-593.

[113] Rauscher, F.H., Shaw, G.L., Levine, L.J., et al. (1997) Music Training Causes Long-Term Enhancement of Preschool Children's Spatial-Temporal Reasoning. Neurological Research, 19, 2-8.

[114] Purnell-Webb, P. and Speelman, C.P. (2008) Effects of Music on Memory for Text. Perceptual and Motor Skills, 106, 927-957. http://dx.doi.org/10.2466/pms.106.3.927-957

[115] Jäncke, L. (2012) The Relationship between Music and Language. Frontiers in Psychiatry, 3, 123.

[116] Kennedy, R. and Scott, A. (2005) A Pilot Study: The Effects of Music Therapy Interventions on Middle School Students’ ESL Skills. Journal of Music Therapy, 42, 244-261. http://dx.doi.org/10.1093/jmt/42.4.244

[117] Silverman, M.J. (2003) Music Therapy and Clients Who Are Chemically Dependent: A Review of Literature and Pilot Study. The Arts in Psychotherapy, 30, 273-281. http://dx.doi.org/10.1016/j.aip.2003.08.004

[118] Baker, F.A., Gleadhill, L.M. and Dingle, G.A. (2007) Music Therapy and Emotional Exploration: Exposing Substance Abuse Clients to the Experiences of Non-Drug-Induced Emotions. The Arts in Psychotherapy, 34, 321-330. http://dx.doi.org/10.1016/j.aip.2007.04.005

[119] Gallant, W., Holosko, M., Gorey, K.M. and Lesiuk, T.L. (1997) Music as a Form of Intervention with Out-Patient Alcoholic Couples: A Quasi-Experimental Investigation. Canadian Journal of Music Therapy, 5, 67-84.

[120] James, M.R. (1988) Adolescent Values Clarification: A Positive Influence on Perceived Locus of Control. Journal of Music Therapy, 25, 206-215. http://dx.doi.org/10.1093/jmt/25.4.206

[121] Winkelman, M. (2003) Complementary Therapy for Addiction: Drumming Out Drugs. American Journal of Public Health, 93, 647-651. http://dx.doi.org/10.2105/AJPH.93.4.647

[122] Good, M., Anderson, G.C., Ahn, S., Cong, X. and Stanton-Hicks, M. (2005) Relaxation and Music Reduce Pain Following Intestinal Surgery. Research in Nursing and Health, 28, 240-251. http://dx.doi.org/10.1002/nur.20076

[123] Richards, T., Johnson, J., Sparks, A. and Emerson, H. (2007) The Effect of Music Therapy on Patients’ Perception and Manifestation of Pain, Anxiety, and Patient Satisfaction. Medsurg Nursing, 16, 7-14.

[124] McCaffrey, R. and Locsin, R. (2006) The Effect of Music on Pain and Acute Confusion in Older Adults Undergoing Hip and Knee Surgery. Holistic Nursing Practice, 20, 218-224. http://dx.doi.org/10.1097/00004650-200609000-00002

[125] Whitehead-Pleaux, A.M., Zebrowski, N., Baryza, M.J. and Sheridan, R.L. (2007) Exploring the Effects of Music Therapy on Pediatric Pain: Phase 1. Journal of Music Therapy, 44, 217-241. http://dx.doi.org/10.1093/jmt/44.3.217

[126] Klassen, J.A., Liang, Y., Tjosvold, L., Klassen, T.P. and Hartling, L. (2008) Music for Pain and Anxiety in Children Undergoing Medical Procedures: A Systematic Review of Randomized Controlled Trials. Ambulatory Pediatrics, 8, 117-128. http://dx.doi.org/10.1016/j.ambp.2007.12.005

[127] Whitehead-Pleaux, A.M., Baryza, M.J. and Sheridan, R.L. (2006) The Effects of Music Therapy on Pediatric Patients' Pain and Anxiety during Donor Site Dressing Change. Music Therapy, 43, 136-153. http://dx.doi.org/10.1093/jmt/43.2.136

[128] Phumdoung, S. and Good, M. (2003) Music Reduces Sensation and Distress of Labor Pain. Pain Management Nursing, 4, 54-61. http://dx.doi.org/10.1016/S1524-9042(02)54202-8

[129] Siedliecki, S.L. and Good, M. (2006) Effect of Music on Power, Pain, Depression and Disability. Journal of Advanced Nursing, 54, 553-562. http://dx.doi.org/10.1111/j.1365-2648.2006.03860.x

[130] Huang, S.T., Good, M. and Zauszniewski, J.A. (2010) The Effectiveness of Music in Relieving Pain in Cancer Patients: A Randomized Controlled Trial. International Journal of Nursing Studies, 47, 1354-1362. 
http://dx.doi.org/10.1016/j.ijnurstu.2010.03.008

[131] Cepeda, M.S., Carr, D.B., Lau, J. and Alvarez, H. (2013) Music for Pain Relief. The Cochrane Database of Systematic Reviews, 10, Article ID: CD004843. http://dx.doi.org/10.1002/14651858.CD004843.pub3

[132] Kumar, A.M., Tims, F., Cruess, D.G., et al. (1999) Music Therapy Increases Serum Melatonin Levels in Patients with Alzheimer's Disease. Alternative Therapies in Health and Medicine, 5, 49-57.

[133] Tsao, J.C.I. (2007) Effectiveness of Massage Therapy for Chronic, Non-Malignant Pain: A Review. Evidence-Based Complementary and Alternative Medicine, 4, 165-179. http://dx.doi.org/10.1093/ecam/nel109

[134] Hunt, E.R. and Johnson, G. (1993) Keeping Chaos at Bay. IEEE Spectrum, 30, 32-36. http://dx.doi.org/10.1109/6.241543

[135] Peitgen, H.O., Jurgens, H. and Saupe, D. (1992) Chaos and Fractals. Springer-Verlag, New York. http://dx.doi.org/10.1007/978-1-4757-4740-9

[136] Abarbanel, H.D.I., Brown, R. and Kennel, M.B. (1991) Lyapunov Exponents in Chaotic Systems: Their Importance and Their Evaluation Using Observed Data. International Journal of Modern Physics B, 5, 1347-1375. http://dx.doi.org/10.1142/S021797929100064X

[137] Verma, A. and Radtke, R. (2006) EEG of Partial Seizures. Journal of Clinical Neurology, 23, 333-339.

[138] Li, Y., Tong, S., Liu, D., et al. (2008) Abnormal EEG Complexity in Patients with Schizophrenia and Depression. Clinical Neurophysiology, 119, 1232-1241. http://dx.doi.org/10.1016/j.clinph.2008.01.104

[139] Nandrino, J.L., Pezard, L., Martinerie, J., et al. (1994) Decrease of Complexity in EEG as a Symptom of Depression. NeuroReport, 5, 528-530. http://dx.doi.org/10.1097/00001756-199401120-00042

[140] Zappasodi, F., Olejarczyk, E., Marzetti, L., et al. (2014) Fractal Dimension of EEG Activity Senses Neuronal Impairment in Acute Stroke. PLoS ONE, 9, e100199. http://dx.doi.org/10.1371/journal.pone.0100199

[141] Raghavendra, B.S., Dutt, D.N., Halahalli, H.N. and John, J.P. (2009) Complexity Analysis of EEG in Patients with Schizophrenia Using Fractal Dimension. Physiological Measurement, 30, 795-808. http://dx.doi.org/10.1088/0967-3334/30/8/005

[142] Jeong J. (2004) EEG Dynamics in Patients with Alzheimer’s Disease. Clinical Neurophysiology, 115, 1490-1505. http://dx.doi.org/10.1016/j.clinph.2004.01.001

[143] Mizuno, T., Takahashi, T., Raymond, Y., Cho, R.Y., et al. (2010) Assessment of EEG Dynamical Complexity in Alzheimer's Disease Using Multiscale Entropy. Clinical Neurophysiology, 121, 1438-1446. http://dx.doi.org/10.1016/j.clinph.2010.03.025

[144] Chikkappa, G., Borner, G., Burlington, H., et al. (1976) Periodic Oscillation of Blood Leukocytes, Platelets, and Reticulocytes in a Patient with Chronic Myelocytic Leukemia. Blood, 47, 1023-1030.

[145] Appleton, R., Beirne, M. and Acomb, B. (2000) Photosensitivity in Juvenile Myoclonic Epilepsy. Seizure, 9, $108-111$. http://dx.doi.org/10.1053/seiz.1999.0376

[146] Muller, P.A., Pascual-Leone, A., Rotenberg, A., et al. (2012) Safety and Tolerability of Repetitive Transcranial Magnetic Stimulation in Patients with Pathologic Positive Sensory Phenomena: A Review of Literature. Brain Stimulation, 5, 320-329. http://dx.doi.org/10.1016/j.brs.2011.05.003

[147] Szelényi, A., Joksimovič, B. and Seifert, V. (2007) Intraoperative Risk of Seizures Associated with Transient Direct Cortical Stimulation in Patients with Symptomatic Epilepsy. Journal of Clinical Neurophysiology, 24, 39-43. http://dx.doi.org/10.1097/01.wnp.0000237073.70314.f7

[148] Sweetow, R. (2013) The Use of Fractal Tones in Tinnitus Patient Management. Noise \& Health, 15, 96-100. http://dx.doi.org/10.4103/1463-1741.110289

[149] Herzfeld, M. and Kuk, F. (2011) A Clinician’s Experience with Using Fractal Music for Tinnitus Management. Hearing Review, 18, 50-55.

[150] Kuk, F., Peeters, H. and Lau, C.L. (2010) The Efficacy of Fractal Music Employed in Hearing Aids for Tinnitus Management. Hearing Review, 17, 32-42.

[151] Golestanirad, L., Elahi, B., Molina, A., et al. (2013) Analysis of Fractal Electrodes for Efficient Neural Stimulation. Frontiers in Neuroengineering, 6, 3. http://dx.doi.org/10.3389/fneng.2013.00003

[152] Barnsley, M.F. (1986) Fractal Functions and Interpolation. Constructive Approximation, 2, 303-329. http://dx.doi.org/10.1007/BF01893434

[153] Dewdney, A.K. (1991) Mathematical Recreations “Leaping into Lyapunov Space”. Scientific American, 265, 178-180. http://dx.doi.org/10.1038/scientificamerican0991-178

[154] Lindenmayer, A. (1968) Mathematical Models for Cellular Interactions in Development. I and II. Journal of Theoretical Biology, 18, 280-315. http://dx.doi.org/10.1016/0022-5193(68)90079-9 
[155] Cannon, J.W., Floyd, W.J. and Parry, W.R. (2001) Finite Subdivision Rules. Conformal Geometry and Dynamics, 5, 153-196. http://dx.doi.org/10.1090/S1088-4173-01-00055-8

[156] Vicsek, T. (1992) Fractal Growth Phenomena. 2nd Edition, World Scientific, Singapore, New York. http://dx.doi.org/10.1142/1407

[157] Goldberger, A.L. (1996) Non-Linear Dynamics for Clinicians: Chaos Theory, Fractals, and Complexity at the Bedside. Lancet, 347, 1312-1314. http://dx.doi.org/10.1016/S0140-6736(96)90948-4 


\author{
Abbreviations \\ $\lambda$ : Lyapunov Exponent \\ ADHD: Attention-Deficit Hyperactivity Disorder \\ AL-TENS: Acupuncture-Like Trancutaneous Electrical Nerve Stimulation \\ APS: Action Potential Stimulation \\ BCM: Beinenstock-Cooper-Munro \\ CaM: Catmodulin \\ CNS: Central Nervous System \\ DBS: Deep Brain Stimulation \\ DPL: Deep Penetrating Light Therapy \\ EBS: Electrical Brain Stimulation \\ ECG: Electrocardiogram \\ EEG: Electroencephalogram \\ EMDA: Electromotive Drug Administration \\ EMS: Electrical Muscle Stimulation \\ EPSC: Excitatory Post-Synaptic Current \\ EPSP: Excitatory Post-Synaptic Potential \\ FES: Functional Electrical Stimulation \\ HIFU: High-Intensity Focused Ultrasound \\ HVPGS: High Voltage Pulsed Galvanic Stimulation \\ IFC: Interferential Current \\ IFT: Interferential Therapy \\ IRR: Infra Red Irradiation \\ LIDC: Low Intensity Direct Current \\ LILT: Low Intensity Laser Therapy \\ LIPUS: Low Intensity Pulsed Ultrasound \\ LLLT: Low-Level Laser Therapy \\ LTD: Long-Term Depression \\ LTP: Long-Term Potentiation \\ MCT: Microcurrent Therapy \\ MDD: Major Depressive Disorder \\ MENS: Microcurrent Electrical Neuromuscular Stimulation \\ MST: Magnetic Seizure Therapy \\ MWD: Microwave Diathermy \\ NMDA: N-methyl-D-aspartate \\ NMES: Neuromuscular Electrical Stimulation \\ OCD: Obsessive-Compulsive Disorder \\ PDSD: Post-Traumatic Stress Disorder \\ PDT: Photodynamic Therapy \\ PEMF: Pulsed Electromagnetic Field \\ PNS: Peripheral Nervous System \\ PSWT: [Pulsed] Shortwave Therapy \\ SCENAR: Self-controlling Energy Neuro Adaptive Regulator \\ SWD: Shortwave Diathermy \\ tDCS: Transcranial Direct Current Stimulation \\ TENS: Transcutaneous Electrical Nerve Stimulation \\ TMS: Transcranial Magnetic Stimulation \\ UVR: Ultraviolet Radiation \\ VNS: Vagus Nerve Stimulation
}


Scientific Research Publishing (SCIRP) is one of the largest Open Access journal publishers. It is currently publishing more than 200 open access, online, peer-reviewed journals covering a wide range of academic disciplines. SCIRP serves the worldwide academic communities and contributes to the progress and application of science with its publication.

Other selected journals from SCIRP are listed as below. Submit your manuscript to us via either submit@scirp.org or Online Submission Portal.
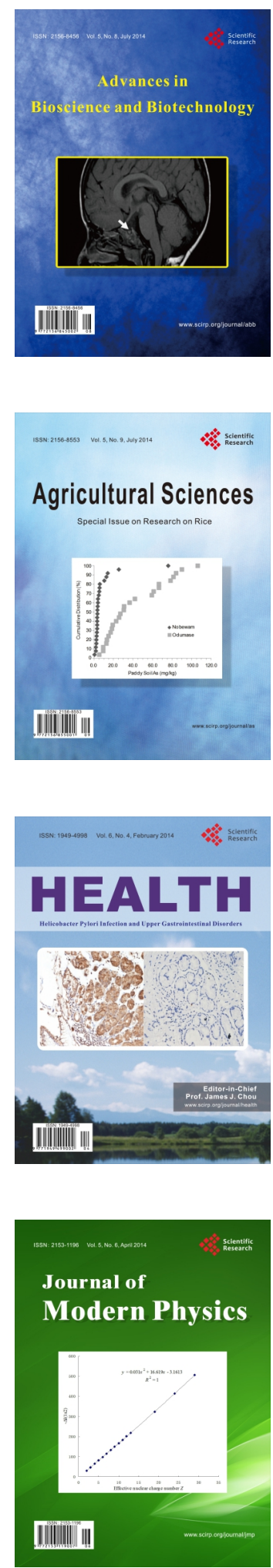
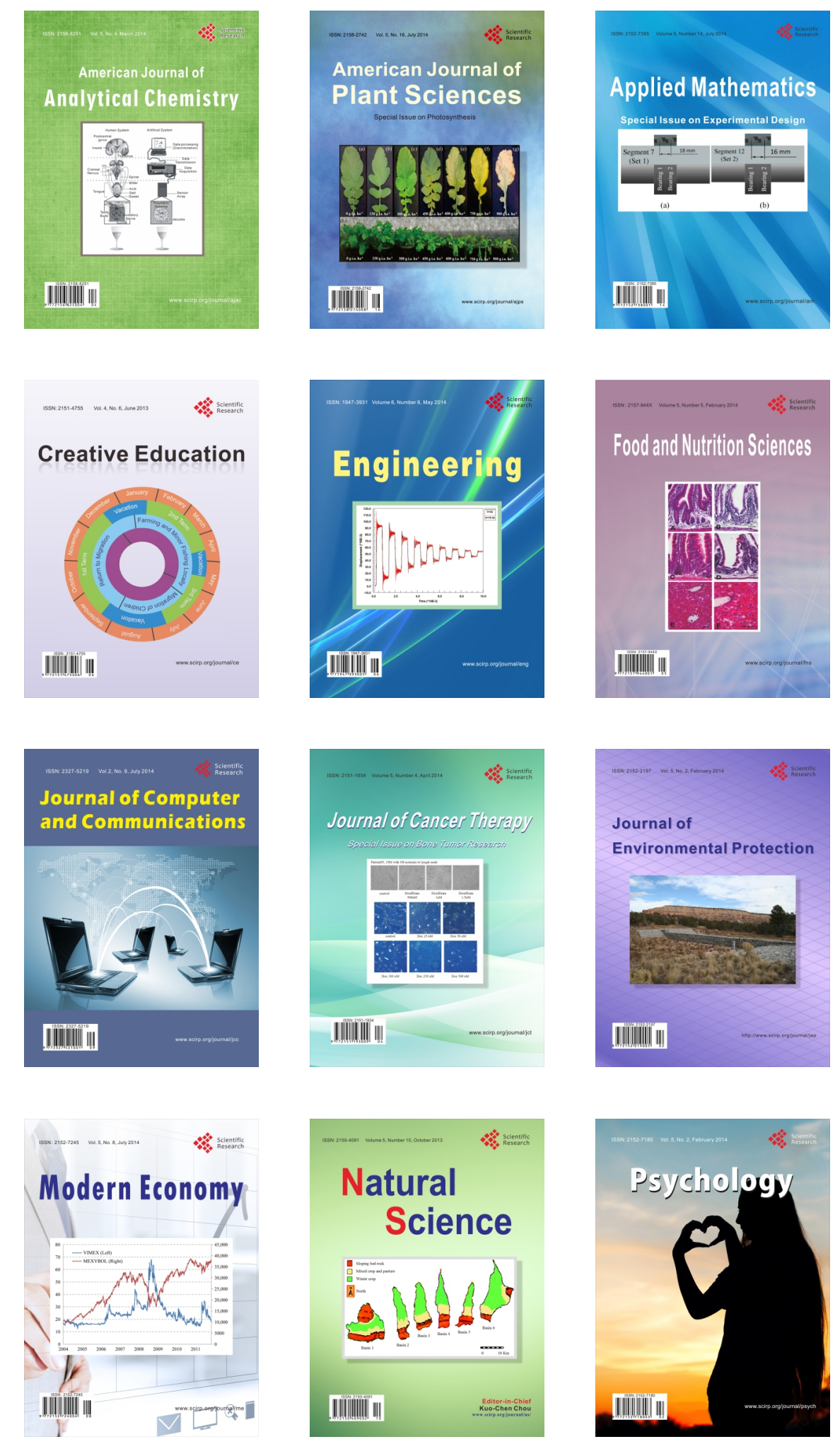